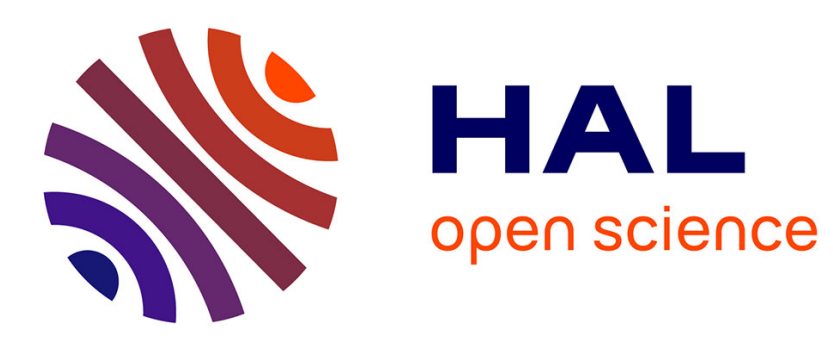

\title{
A study of the plasma electronegativity in an argonoxygen pulsed-dc sputter magnetron
}

Sd You, R Dodd, A Edwards, Jw Bradley

\section{To cite this version:}

Sd You, R Dodd, A Edwards, Jw Bradley. A study of the plasma electronegativity in an argonoxygen pulsed-dc sputter magnetron. Journal of Physics D: Applied Physics, 2010, 43 (50), pp.505205. 10.1088/0022-3727/43/50/505205 . hal-00629979

\section{HAL Id: hal-00629979 \\ https://hal.science/hal-00629979}

Submitted on 7 Oct 2011

HAL is a multi-disciplinary open access archive for the deposit and dissemination of scientific research documents, whether they are published or not. The documents may come from teaching and research institutions in France or abroad, or from public or private research centers.
L'archive ouverte pluridisciplinaire HAL, est destinée au dépôt et à la diffusion de documents scientifiques de niveau recherche, publiés ou non, émanant des établissements d'enseignement et de recherche français ou étrangers, des laboratoires publics ou privés. 


\title{
A study of the plasma electronegativity in an argon-oxygen pulsed-DC sputter magnetron
}

\author{
SD You, R Dodd, A Edwards and JW Bradley* \\ Department of Electrical Engineering and Electronics, \\ University of Liverpool, Brownlow Hill, Liverpool, L69 3GJ, UK
}

*Author for correspondence

\begin{abstract}
Using Langmuir probe-assisted laser photodetachment, the temporal evolution of the $\mathrm{O}^{-}$density has been determined in the bulk plasma of a unipolar pulsed-dc magnetron. The source was operated in reactive mode, at a fixed nominal on-time power of $100 \mathrm{~W}$, sputtering $\mathrm{Ti}$ in argon-oxygen atmospheres at $1.3 \mathrm{~Pa}$ pressure, but over a variation of duty cycles from 5 to $50 \%$ and oxygen partial pressures of 10 and $50 \%$ of the total pressure.
\end{abstract}

In the plasma on-time, for all duty cycles the negative ion density (n.) rises marginally reaching values typically less than $2 \times 10^{15} \mathrm{~m}^{-3}$ with negative ion-to-electron density ratios, $\alpha<1$. However, immediately after the transition from pulse on-to-off, $\mathrm{n}$ - falls by about $20-30 \%$ as fast $\mathrm{O}^{-}$species

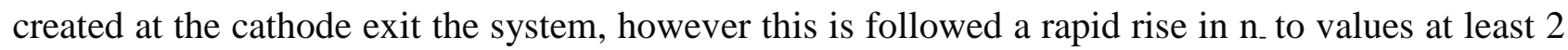
or 3 times that in the on-time. The rate of rise of $n$. and its maximum value both increase with decreasing duty cycle. In the off-time, the electron density falls rapidly (initial decay rates of several 10's of $\mu \mathrm{s}$ ), and therefore the afterglow plasma becomes highly electronegative, with $\alpha$ reaching 4.6 and 14.4 for 10 and $50 \%$ oxygen partial pressure respectively. The rapid rise in $\mathrm{n}_{\text {- in }}$ the afterglow (in which the electron temperature falls from about 5 to $0.5 \mathrm{eV}$ ) is attributed to the dissociative attachment of highly-excited oxygen matastables, which themselves are created in the pulse on-time. At the lowest duty of $5 \%$, the long-term $\mathrm{O}^{-}$decay times are several 100's of $\mu$ s.

Langmuir probe characteristics show the clear signature that negative ions dominate over the electrons in the off-time. From the ion and electron saturation current ratios, $\alpha$ has been estimated in some chosen cases and found to agree within a factor between 2 and 10 with those obtained more directly from the photodetachment method. 


\section{Introduction}

In the reactive magnetron sputter deposition of oxide thin-films, when metal targets (M) are sputtered in oxygen-argon gas mixtures or ceramic targets are sputtered in pure argon, copious amounts of negative ions (e.g. $\mathrm{O}^{-}, \mathrm{O}_{2}^{-}, \mathrm{O}_{3}{ }^{-}$and $M O_{x}^{-}$) can be created at the target [1]. These ions are accelerated through the cathode sheath to bombard the substrate with highest energies equivalent to the target potential, that is, many 100's of eV [2,3]. They easily overcome the negative substrate bias potentials used to attract positive ions and can be potentially destructive in the growth of engineering quality films. Mass spectrometric studies have shown that the dominant ion is $\mathrm{O}^{-}$[4] and their production increases as the secondary electron emission coefficient of the target material increases [5]. Interestingly, it has been shown that the magnetic field configuration of the magnetron has a strong influence on the spatial distribution of these fast negative ions [6].

In many reactive magnetron diagnostic studies, negative oxygen ions are usually detected by energy-resolved mass spectrometry. Although this technique is very powerful in revealing to high precision the energies of the ions and hence information on their creation, without painstaking calibration, using pure ion sources, it only really provides a qualitative picture of the relative fluxes of species arriving at a boundary. Studies to date have shown the dominant ion is $\mathrm{O}^{-}$with energy distribution functions consisting of three main peaks [3]. These components are at high, medium and low energy. From the measured negative ion energy distributions and based on calculations Mráz S and Schneider [2] have proposed a number of possible mechanisms for their formation. The high energy ions, with energies up to the equivalent of the target potential are generated by desorption of $\mathrm{O}^{-}$or $\mathrm{O}$ at the target followed by electron attachment and accelerated over the cathode fall. Medium energy ions, with a large fraction or integer fraction of the of the target potential are generated either by the sputtering of $M O_{x}^{-}$clusters which are acceleration over the cathode fall and subsequently suffer spontaneous dissociation or by collisionaly induced dissociation of $\mathrm{O}_{2}^{-}$itself accelerated by the full target potential. In that later case $\mathrm{O}^{-}$will appear with half the target potential. The detected low-energy negative ions (in the few eV range) are those that have lost most of their energy by suffering many collisions en route. However, there is a very large component of cold negative ions with temperatures significantly less than the electron temperature (and not much above the gas temperature i.e. $<1 \mathrm{eV}$ ) which are not detected by the mass spectrometer, since they cannot overcome the sheath potential barrier between the plasma and the sampling orifice to enter the instrument. In low pressure DC plasma systems, including the magnetron, where the electron 
temperatures are above 3 or $4 \mathrm{eV}$ these negative ions will be formed by dissociative electron attachment of the ground state oxygen molecule $\mathrm{O}_{2}\left(\mathrm{X}^{3} \sum_{\mathrm{g}}\right)$ [7], providing negative ion densities typically less than the electron density. In pulsed plasmas, particularly in the off-time when the electrons cool, $\mathrm{O}^{-}$can be created in high concentrations, it is believed, by the dissociative electron attachment of the highly electronically excited metastable oxygen $O_{2}^{M}\left(A^{3} \Sigma_{u}^{+}, C^{3} \Delta_{u}, c^{1} \Sigma_{u}^{-}\right)$[8]. In the afterglow, as the sheath barrier between the mass spectrometer and the plasma collapses, these ions may enter the instrument and be detected.

Recently, the negative ion $\left(\mathrm{O}^{-}\right)$density has been measured in reactive magnetron sputtering plasmas. This was done using a Langmuir probe in both DC balanced and unbalanced magnetron configurations [9] and by Langmuir probe-assisted laser photo-detachment in a DC [10] and bipolar-pulsed magnetron [11]. It was found in the driven phase, the degree of electronegativity, i.e. $\alpha=\mathrm{n} / \mathrm{n}_{\mathrm{e}}$ varies from about $0.1-0.6$, increasing with oxygen partial pressure, decreasing with applied power and degree of magnetic unbalance. In [11] it was shown that the energetic negative ions created at the target make up approximately $10 \%$ of the total negative ion concentration with the remaining $90 \%$ (of low or thermal energy) created in the plasma bulk. Despite the restricted short off-time of $5 \mu$ s used in [11], there was some evidence that $\mathrm{O}^{-}$densities do start to rise in the off-time. In this work we investigate further this phenomenon using a specially engineered pulse power supply that allows much long off-times and therefore the possibility to observe the long-term evolution of the $\mathrm{O}^{-}$density in the afterglow.

The presence of negative ions is important if not crucial in many reactive sputter applications, with energetic species arriving at the growing film potentially leading to detrimental effects such as ioninduced damage [12,13,14], and the reduction in crystallinity [15] and resistivity [16] of functional films. Since a sizable fraction of the negative ions carry considerable energy and momentum it has been calculated that the energy flux to a substrate from the negative ions in the driven phase of the discharge can be significantly higher than that from the positive ions [11]. The larger fraction of low-energy (or thermal) negative ions created in the plasma bulk although not able to reach the substrate can alter the properties of the entire discharge, including the boundary sheaths [17], affecting the process and deposition characteristics.

Although the quantitative studies of the $\mathrm{O}^{-}$density in the magnetron using photodetachment $[10,11]$ have been useful, the power delivery modes used, namely DC and $100 \mathrm{kHz}$ DC bi-polar pulsing have not allowed the study of the long term-evolution of the negative ions, for instance in an extended afterglow. Not only this, the presence of fast transients of high amplitude in the voltage 
waveforms between on-to-off and off-to-on phases of the bi-polar DC pulse [11] prevented good Langmuir probe data to be collected for large fractions of the pulse period $(\sim 4 \mu$ s out of the total 10 $\mu \mathrm{s})$. Here, we investigate the negative ion dynamics in a uni-polar pulsed magnetron system, with reduced voltage transients and ringing and with long off-times up to $950 \mu \mathrm{s}$.

\section{Experimental arrangement}

\subsection{The magnetron sputtering and photodetachment systems}

The experimental set up is shown in figure 1. A detailed description of the vacuum and diagnostic systems can be found in reference [10]. The magnetron, fitted with a $150 \mathrm{~mm}$ diameter titanium target, was operated using a in-house built pulse chopper unit driven by the DC output from an Advanced Energy Inc. Pinnacle Plus power supply. The voltage waveforms consisted of regular square voltage pulses. Here we chose a fixed on-time duration of $50 \mu \mathrm{s}$, and varied the off-time from 50 to $950 \mu$ s to give duty cycles of $50,25,12.5$ and $5 \%$. The energy delivered in the on-time was fixed nominally at $5 \mathrm{~mJ} /$ pulse (on-time power of $100 \mathrm{~W}$ ). Therefore, as the off-time durations were increased the time-averaged powers decreased from 50 to $5 \mathrm{~W}$. The highest power was limited by the capability of the chopper circuit. These powers are somewhat lower than those used in most sputtering applications, however, the experimental approach and reaction chemistry considered here will be transferable to studies with higher power magnetron plasmas, even if higher powers yield very different negative ion densities. The total working pressure was set at $1.33 \mathrm{~Pa}$ (10 mtorr) using a Baratron pressure gauge and a feedback control unit. The oxygen partial pressures was regulated to be either 10 or $50 \%$ of the overall total pressure, and we denote these settings in the text as $\mathrm{P}_{\mathrm{O} 2} / \mathrm{P}_{\mathrm{O} 2+\mathrm{Ar}}=0.1$ and 0.5 respectively. The $\mathrm{O}_{2}$ partial pressure was determined in the presence of the plasma. A delay pulse generator, (Stanford DG535), was used to control the timing and synchronisation of both the Langmuir probe and laser system.

The laser system chosen to perform the Langmuir probe-assisted photodetachment was a pulsed Qswitched Nd: YAG laser (Quantel Brilliant B) operating at a wavelength of $532 \mathrm{~nm}$ with pulse widths of 6 to $8 \mathrm{~ns}$. The laser beam diameter was fixed at $4 \mathrm{~mm}$ and the laser energy set to provide

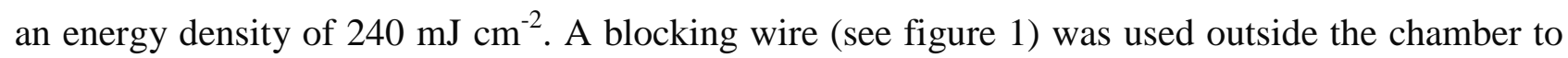
create a shadow on the probe. This technique helps reduce significantly any ablation of insulating material deposited on the probe and therefore the generation of spurious probe signals [18]. During the photodetachment experiments a variable DC power supply in series with a resistor was used to electrically bias the probe. 
To faithfully transform the detected photo-electron current to a voltage signal and remove the DC background with minimal distortion a capacitor and two resistors where used to form a high-pass filter circuit as described in [10]. PSPICE simulations and bench tests show the circuit to have a -3 dB lower frequency cut-off at $30 \mathrm{~Hz}$ and a (10\% attenuation) high-frequency cut-off at $15.8 \mathrm{MHz}$.

The detachment fraction $\left(\Delta n_{-} / n_{-}\right)$of the bulk negative ions of density $\left(n_{-}\right)$is dependent on the incident photon energy density and the photodetachment cross-section $\left(\sigma_{p d}\right)$. For single species photodetachment this is given by [19]

$$
\frac{\Delta n_{-}}{n_{-}}=1-\exp \left(-\frac{E}{S} \frac{\sigma_{p d}}{h v}\right)
$$

Where $E$ is the incident laser energy and $S$ is the beam cross-sectional area. The photodetachment cross-sections for $\mathrm{O}^{-}$is $6.5 \times 10^{-18} \mathrm{~cm}^{2}$ at $532 \mathrm{~nm} \mathrm{[10]}$.

The Langmuir probe used to collect both the photodetachment electron current and the native background electron current was situated on the discharge centre line $75 \mathrm{~mm}$ from the target with its length perpendicular to the normal of the target (see figure 2). The probe itself consisted of a 250 $\mu \mathrm{m}$ diameter tungsten wire housed in a re-entrant ceramic sleeve (always located outside of the laser beam). The $7 \mathrm{~mm}$ long extension of the ' $L$ ' shaped probe tip ( $3 \mathrm{~mm}$ short extension) was aligned co-axially with the laser beam. This was positioned centrally by having the stem offset by $3.5 \mathrm{~mm}$. To obtain conventional time-resolved Langmuir probe current-voltage characteristics an ESPion probe acquisition system (from HIDEN Analytical Ltd) was synchronised with the magnetron voltage supply. The time-resolution of the Langmuir probe characteristics was $1 \mu \mathrm{s}$.

The magnetic field configuration of the magnetron is a typical type II unbalanced geometry, with the outer magnetic poles being stronger than the inner pole, producing field lines that funnel into the centre as shown in figure 2 . The magnetic field strength at the probe position was $\sim 20$ Gauss. For this field strength, low temperature electrons $\left(\mathrm{kT}_{\mathrm{e}}<0.1 \mathrm{eV}\right)$ will be magnetised (their Larmour radii $<$ probe radius) with their collection at the probe being reduced. This may be important for the photo-electrons. However, since the photodetached electrons have initial energies of $0.74 \mathrm{eV}$ (the 
photon energy minus the electron affinity [19]) and are substantially thermalized (acquire the same temperature as the background electrons) on the timescale of their collection [10] the ratio of the photodetached-to-background electron currents will not vary with magnetic field. It is this ratio that is used to determine the negative ion-to-electron density ratio $\alpha$.

At an optimal probe bias $\mathrm{V}_{\mathrm{b}-\mathrm{opt}}$ the photodetached electron current $\Delta \mathrm{I}_{\mathrm{pd}}$ and background electron current $I_{e}$ can be used to determine the negative ion density $n_{\text {. }}$ using the equation $n_{-}=n_{e}\left(\Delta I_{p d} / I_{e}\right)$, where $n_{e}$ is the electron density obtained from the Langmuir probe characteristic. The optimum probe bias $\mathrm{V}_{\mathrm{b} \text {-opt }}$ is chosen to be that corresponding to the maximum in the calculated ratio $\Delta \mathrm{I}_{\mathrm{pd}}\left(\mathrm{V}_{\mathrm{b}}\right) / \mathrm{I}_{\mathrm{e}}\left(\mathrm{V}_{\mathrm{b}}\right)$ plotted against probe bias $\mathrm{V}_{\mathrm{b}}$ as described in [10]. To obtain $\mathrm{n}_{\mathrm{e}}$ from the probe data

we used the equation $n_{e}=\frac{I_{e-s a t}}{A e \sqrt{8 k T_{e} / \pi m_{e}}}$ where $\mathrm{I}_{\mathrm{e}-\mathrm{sat}}$ is the electron saturation current (obtained at the plasma potential $V_{p}$ ), $T_{e}$ is the electron temperature, $m_{e}$ the electron mass, $A$ the probe area and e the electronic charge. We can assume the contribution from the negative ions (with mass M. $>>$ $\mathrm{m}_{\mathrm{e}}$ and temperatures $\mathrm{T}_{-} \ll \mathrm{T}_{\mathrm{e}}$ ) to the total random current measured at bias $\mathrm{V}_{\mathrm{b}}=\mathrm{V}_{\mathrm{p}}$ as being negligible. The electron temperature was determined from the inverse slope of the electron current $I_{e}$ in the electron retarding region of the characteristic versus $V_{b}$.

Figures $3 \mathrm{a}$ and $\mathrm{b}$, show representative discharge voltage $\mathrm{V}_{\mathrm{d}}$ and current $\mathrm{I}_{\mathrm{d}}$ waveforms as well as the calculated power $\mathrm{P}_{\mathrm{d}}$ recorded at a test box close to the magnetron cathode for the cases of a $50 \%$ and a $5 \%$ duty cycle with $10 \%$ oxygen partial pressure. The corresponding traces at $50 \%$ oxygen partial pressure have the same form. We define $t=0$ as the beginning of the on-time. For large duty cycles e.g. 50\%, the initial voltage, current and power waveforms are characterised by a spike and a local minimum at times $\mathrm{t}<1 \mu \mathrm{s}$ after pulse initiation, while for short duty cycles, e.g. $5 \%, \mathrm{~V}_{\mathrm{d}}$ has a spike at greater times, i.e. $\mathrm{t} \sim 5 \mu$ s, however there is no minimum in the waveforms and $\mathrm{I}_{\mathrm{d}}$ and $\mathrm{P}_{\mathrm{d}}$ rise monotonically. To avoid any spurious values in the measured plasma parameters no Langmuir probe measurements were made during the initial transient phases up to $t=10 \mu \mathrm{s}$. The estimated error in the probe measurements is $\pm 20 \%$ for $n_{e}$ and $\pm 20 \%$ for $T_{e}$ with the error in $\alpha$ being $\pm 16 \%$ [10]. The associated error in calculated values of $n_{\text {. }}$ is $\pm 30 \%$.

\section{The photodetachment and Langmuir probe results}

Figures 4, 5, 6 and 7 show the time-evolution of the measured values of $\mathrm{n}_{\mathrm{e}}, \mathrm{T}_{\mathrm{e}}(\mathrm{in} \mathrm{eV}), \mathrm{n}_{-}$and $\alpha\left(=\mathrm{n}_{\text {. }}\right.$ $/ \mathrm{n}_{\mathrm{e}}$ ) for the four different chosen duty cycles with $\mathrm{P}_{\mathrm{O} 2} / \mathrm{P}_{\mathrm{O} 2+\mathrm{Ar}}=0.1$. Figures $8,9,10$ and 11 show the same for $\mathrm{P}_{\mathrm{O} 2} / \mathrm{P}_{\mathrm{O} 2+\mathrm{Ar}}=0.5$. No photodetachment-probe measurements were made during the transient 
phase between plasma off-and-on phases at $t=0 \mu$ s since the plasma potential $V_{p}$ has a large positive spike (up to $+10 \mathrm{~V}$ ) persisting for a few $\mu$ s in this period and probe measurements become unreliable. This rapid increase in $\mathrm{V}_{\mathrm{p}}$ over normal values close to ground potential will reduce fast electron loss from the discharge so preserving quasi-neutrality. In figures 4 and 8 the dependency of $\mathrm{n}_{\mathrm{e}}$ on instantaneous discharge power is also shown.

\subsection{The electron density, $n_{e}$}

In figures 4 and 8 we see from both the on and off-times a consistent picture of the discharge dynamics, in which the electron density evolves independently of the duty cycle, that is, the different initial and final values of $\mathrm{n}_{\mathrm{e}}$ at the beginning and end of the pulse for different off-times do not influence the on-time rise rates in $\mathrm{n}_{\mathrm{e}}$. In the off-time, the characterise the decay time in electron density at different stages of the afterglow has been determined from a plot of $\operatorname{Ln}\left(\mathrm{n}_{\mathrm{e}}\right)$ against time (not shown). This reveals in all cases considered a two-fold decay, with an initial and final decay. For instance, at $\mathrm{P}_{\mathrm{O} 2} / \mathrm{P}_{\mathrm{O} 2+\mathrm{Ar}}=0.1$ and $5 \%$ duty cycle, the characteristic time for the initial decay in $\mathrm{n}_{\mathrm{e}}$ is $40 \mu \mathrm{s}$, lengthening to $244 \mu \mathrm{s}$ for times greater than $50 \mu \mathrm{s}$ into the afterglow. These times vary only marginally with duty cycle. For $\mathrm{P}_{\mathrm{O} 2} / \mathrm{P}_{\mathrm{O} 2+\mathrm{Ar}}=0.5$ the $\mathrm{n}_{\mathrm{e}}$ profiles show initial and long-term characteristic decay times of $11 \mu \mathrm{s}$ and $108 \mu \mathrm{s}$ somewhat quicker than the $\mathrm{P}_{\mathrm{O} 2} / \mathrm{P}_{\mathrm{O} 2+\mathrm{Ar}}=0.1$ case. The general forms of the electron density profiles are consistent with a global model of a pulsed plasma system (in oxygen) [20]. In both $\mathrm{O}_{2}$ partial pressure cases, in the driven phase of the discharge the electron density increases linearly with the instantaneous discharge power $(\mathrm{P})$, for all the duty cycles, (see the inserts in figures 4 and 8). This dependency we may expect since the discharge power $\mathrm{P} \propto \mathrm{n}_{\mathrm{e}}[20]$.

\subsection{The electron temperature, $T_{e}$}

Consistent with the electron density profiles, the time evolution of $\mathrm{T}_{\mathrm{e}}$ seems to be independent of the pulse history with all profiles following the same trend line, however with the starting value of $\mathrm{T}_{\mathrm{e}}$ depending on the final value from the previous pulse (see figures 5 and 9 ). For $\mathrm{P}_{\mathrm{O} 2} / \mathrm{P}_{\mathrm{O} 2+\mathrm{Ar}}=0.1$, an initial peak in $T_{e}$ is observed at start of the on-time as predicted in [20], however this is not observed at the higher $\mathrm{O}_{2}$ concentration. $\mathrm{T}_{\mathrm{e}}$ remains flat in the on-time, but shows a very fast drop at the beginning of pulse off, with initial characteristic decay times of $\sim 6 \mu$ s for $\mathrm{P}_{\mathrm{O} 2} / \mathrm{P}_{\mathrm{O} 2+\mathrm{Ar}}=0.1$ and $\sim 4 \mu$ s for $\mathrm{P}_{\mathrm{O} 2} / \mathrm{P}_{\mathrm{O} 2+\mathrm{Ar}}=0.5$. Further into the afterglow, up to $200 \mu \mathrm{s}$, these times lengthen to about 120 and $37 \mu$ s respectively. It does appear that the higher the $\mathrm{O}_{2}$ content in the discharge the faster the loss in both electron density and energy in the afterglow. For times $>200 \mu$ s (for the small duty 
cycle cases) the electron temperature does not continue to decrease but actually appears to rise slowly reaching 0.75 and $1 \mathrm{eV}$ after $980 \mu \mathrm{s}$ in the two oxygen partial pressure cases respectively. This effect has been mentioned in relation to other electronegative oxygen discharges [21]. Although it is possible that superelastic collisions between electrons and highly excited $\mathrm{O}_{2}$ or $\mathrm{Ar}$ metastables could be responsible for this re-heating in the afterglow, we cannot rule out that error in obtaining $T_{e}$ from the probe characteristic when $T_{e}$ is small may give the impression the temperature is rising.

\subsection{The $\mathrm{O}^{-}$density, $\mathrm{n}$.}

From figures 6 and 10 we see that $n$. is highly modulated by the pulse, with the temporal evolution

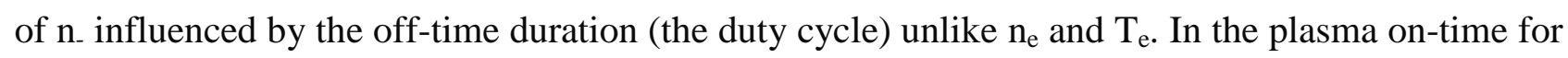
$\mathrm{P}_{\mathrm{O} 2} / \mathrm{P}_{\mathrm{O} 2+\mathrm{Ar}}=0.1$ and all duty cases except $5 \%$, n. decreases at first (times up to $20 \mu \mathrm{s}$ ) but then slowly rises. For 5\% duty n. rises throughout this period. During the on-to-off transition, n. falls in each case by about 20-30 \% as the component of fast (beam-like) negative ions (energy $\sim \mathrm{eV}_{\mathrm{d}}=$ $350 \mathrm{eV}$ and velocity $\sim 7 \times 10^{4} \mathrm{~ms}^{-1}$ ) coming from the target exit the system as described in [11], i.e. they cross the $75 \mathrm{~mm}$ gap between target and probe. This time can be estimated to be about $7.5 \mathrm{x}$ $10^{-2} \mathrm{~m} / 7 \times 10^{4} \mathrm{~ms}^{-1} \sim 1 \mu \mathrm{s}$. In the off time, $\mathrm{n}$. rises to values well above those in the on-time at rates

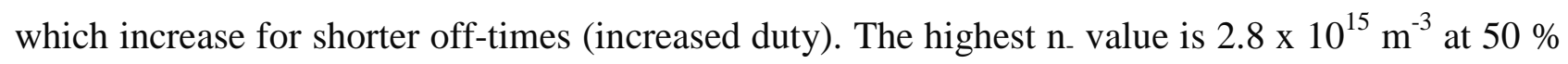
duty. For the longest off-time we can see that n. reaches a turning point (peak) $450 \mu$ s into the afterglow after which it decays with a characteristic time of $\sim 300 \mu \mathrm{s}$. For $\mathrm{P}_{\mathrm{O} 2} / \mathrm{P}_{\mathrm{O} 2+\mathrm{Ar}}=0.5$ the highest values of $\mathrm{n}$. are up to about $30 \%$ higher than for $\mathrm{P}_{\mathrm{O} 2} / \mathrm{P}_{\mathrm{O} 2+\mathrm{Ar}}=0.1$, with generally similar

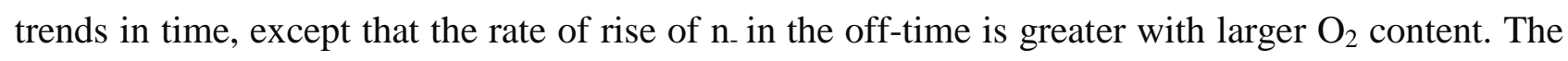
long term decay times of $\mathrm{n}_{-}$is $\sim 200 \mu \mathrm{s}$, and we observe distinct maxima in $\mathrm{n}_{\text {. }}$ in the afterglow for all duty cycle cases.

\subsection{Electronegativity, $\alpha$}

The plotted values of $\alpha$ in figure 7 and 11 reflect the dynamics of $n_{-}$and $n_{e}$ throughout the pulse cycle. For both $\mathrm{O}_{2}$ partial pressures cases $\alpha$ is less than unit in the plasma on-time (i.e. the plasma is weakly electronegative). We observe in all cases except for $5 \%$ duty at $\mathrm{P}_{\mathrm{O} 2} / \mathrm{P}_{\mathrm{O} 2+\mathrm{Ar}}=0.1 \alpha$ initially falls in the on-time as the destruction rate of negative ions increases and $n_{e}$ increases as the discharge power is built-up. After the transition from on-to-off phases there is an approximately linear (and rapid) rise in $\alpha$ for all duty cycles, at rates of $\mathrm{d} \alpha / \mathrm{dt} \sim 10^{4} \mathrm{~s}^{-1}$ for $\mathrm{P}_{\mathrm{O} 2} / \mathrm{P}_{\mathrm{O} 2+\mathrm{Ar}}=0.1$ and $\mathrm{d} \alpha / \mathrm{dt}=1.5 \times 10^{4} \mathrm{~s}^{-1}$ for $\mathrm{P}_{\mathrm{O} 2} / \mathrm{P}_{\mathrm{O} 2+\mathrm{Ar}}=0.5$, with the rate of growth of $\alpha$ being independent of the off- 
time duration. In the case of $5 \%$ duty, $\alpha$ reaches values of 4.6 and 14.4 for $\mathrm{P}_{\mathrm{O} 2} / \mathrm{P}_{\mathrm{O} 2+\mathrm{Ar}}=0.1$ and 0.5 respectively, so the afterglow plasma can be considered strongly electronegative.

\subsection{Langmuir probe study of the extended off-phase}

In the long afterglow the plasma becomes sufficiently electronegative that $\alpha$ can be determined from the Langmuir probe characteristics. This is achieved through determining the ratio of the electron and ion saturation currents, $\mathrm{I}_{-} / \mathrm{I}_{\mathrm{i}}$. Figure 12 shows a set of Langmuir probe characteristics for different times during the pulse period with a $5 \%$ duty cycle and $\mathrm{P}_{\mathrm{O} 2} / \mathrm{P}_{\mathrm{O} 2+\mathrm{Ar}}=0.5$. In the afterglow with $\alpha>1$ the curves become more symmetric (around the floating potential) as the collected electron current falls in relation to the ion current. At $980 \mu \mathrm{s}$, the ratio of electron-to-ion saturation current actually falls below unity. To use probe theory it is necessary to know how the ion saturation current varies with increased plasma electronegativity. Given a value of $\alpha, T_{e}$ and $T_{\text {. }} a$ theoretical ion current $I_{i}$ can be determined from a modified form of the Bohm criterion in the presence of negative ions, using a number of models. Using spherical probe geometry a relationship between $\alpha$ and $\mathrm{I}_{-} / \mathrm{I}_{+}$been determined for different ratios of electron to negative ion temperature $\gamma=$ $\mathrm{T}_{\mathrm{e}} / \mathrm{T}_{\text {- [17] }}$ and used to predict $\alpha$ values in [22]. These predictions are also valid for infinitely long cylindrical probes. In figure 13 we plot the theoretical current ratio $\mathrm{I}_{-} / \mathrm{I}_{+}$normalized by the ratio in the total absence of negative ions as a function of $\alpha$ assuming $\gamma=5$, which is realistic for our case (since we assume $\mathrm{T}_{-} \sim \mathrm{T}_{\text {gas }}=300-800 \mathrm{~K}[23,24]$ ). In figure 13 we also plot the same relationship for the current ratio derived from planar fluid theory [25] for $\gamma=5$, together with the case where $\gamma=1$ (the electrons and negative ions are indistinguishable) and no modified Bohm criterion condition is required.

For the fluid theory we use the analytical approximations,

$I_{+}=n_{e o} C_{s} A e\left(\frac{1}{2}+\frac{\alpha}{\gamma}\right)$ for $\alpha<1$ and $I_{+}=n_{e o} C_{s} A e \frac{1}{\sqrt{\gamma}}\left(\left(\frac{1}{2}\right)^{\frac{1}{\gamma}}+\frac{\alpha}{2}\right)$ for $\alpha>1$ where $\mathrm{n}_{\mathrm{eo}}$ is the remote electron density and $C_{s}=\sqrt{ }\left(k T_{e} / M_{+}\right)$is the ion acoustic speed in the absence of negative ions and $\mathrm{M}_{+}$the average ion mass. These solutions converge well at $\alpha \sim 2$. As we can see from figure 13 the normalized solution for the particle and fluid models are in almost exact agreement and we can use either of them to determine $\alpha$ for our measured ion and electron saturation currents.

Figure 14 shows the predictions for $\alpha$ from probe theory and those values determined from the photodetachment study. We chose the particular cases of the $5 \%$ duty cycle and $\mathrm{P}_{\mathrm{O} 2} / \mathrm{P}_{\mathrm{O} 2+\mathrm{Ar}}=0.1$ 
and 0.5. From the plot we see that the calculated value of $\alpha$ are in general higher than the photodetached measurements (in some cases by an order of magnitude), with the best fit occurring when we assume the negative ion temperature is close to the electron temperature (i.e. $\gamma=1$ as used in [9]). We assign an error in the Langmuir probe determination of $\alpha$ as $\pm 50 \%$ (following [22]). Since we expect the bulk of the negative ions to be cool $(<0.1 \mathrm{eV})$, it may indicate that there is an over estimate in the electron temperature from the probe curves, particularly in the afterglow. The large calculated values of $\alpha$ are a manifestation of the electron-to-ion current ratios in the probe characteristics being smaller than expected. However, any effect from the B-field which may reduce the electron current can be neglected since the currents are normalized to the case with no oxygen present. Although the two methods of determining $\alpha$ only agree to within a factor 10 in the worst cases (and from $<2$ to 5 in the best cases in the long afterglow), there is a strong correlation (trend line) which does show the applicability of using Langmuir probes to at least indicate the presence of negative ions when they are in high concentrations and also to produce a rough estimate of the value of $\alpha$, as already demonstrated in [9] and [22].

\section{Discussion}

In the on-phase of the discharge $\mathrm{O}^{-}$will be created largely through dissociative electron attachment of the $\mathrm{O}_{2}$ molecule $\mathrm{O}_{2}+\mathrm{e}^{-} \rightarrow \mathrm{O}^{-}+\mathrm{O}$ [21], with a threshold energy of $4.7 \mathrm{eV}$ and a rate coefficient that increases with electron temperature $\mathrm{T}_{\mathrm{e}}$. The main loss process will be by ion-ion recombination [10]. In the off-phase as $\mathrm{T}_{\mathrm{e}}$ falls (from about 5 to $0.5 \mathrm{eV}$ in about $10-15 \mu \mathrm{s}$, see figures 5 and 9) the production rate through the reaction $\mathrm{O}_{2}+\mathrm{e}^{-} \rightarrow \mathrm{O}^{-}+\mathrm{O}$ becomes negligible, however as we can see

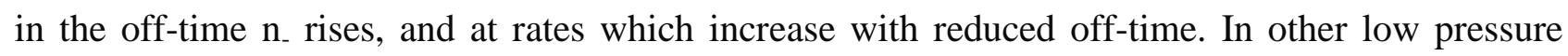
pulsed plasmas rising $\mathrm{O}^{-}$densities in the afterglow have also been observed $[8,21,26,27]$ and the production of $\mathrm{O}^{-}$(in the cooling plasma) can be explained through the electron attachment to metastable $\mathrm{O}_{2}^{M}, \mathrm{O}_{2}^{*}\left(\mathrm{a}^{1} \Delta_{\mathrm{g}}\right)$ or high Rydberg states of the $\mathrm{O}_{2}$ molecules present in the discharge. One likely candidate reaction, due to the high probability of forming negative ions at low electron temperatures, is $e+O_{2}^{M} \rightarrow O^{-}+O$ where $O_{2}^{M}=\left(A^{3} \Sigma_{u}^{+}, C^{3} \Delta_{u}, c^{1} \Sigma_{u}^{-}\right)$are highly excited metastable oxygen molecules (possible in high vibrational levels [28]) created mostly in the plasma on-time. This reaction channel has a rate coefficient $\left(\mathrm{k}_{\mathrm{at}}{ }^{\mathrm{M}}\left(\mathrm{T}_{\mathrm{e}}\right)\right)$ which increases markedly with deceasing $\mathrm{T}_{\mathrm{e}}$, reaching $\sim 10^{-9} \mathrm{~cm}^{3} \mathrm{~s}^{-1}$ for $\mathrm{kT}_{\mathrm{e}}<0.5 \mathrm{eV}$ [8]. 
Although we do not have any direct evidence from this study for the existence of $O_{2}^{M}$ in the discharge we can anticipate what the main creation and destruction reactions are involving $O_{2}^{M}$ as an intermediary for the production of $\mathrm{O}^{-}$(and state their rate coefficients). Through this, the strong dependency of the $\mathrm{O}^{-}$density on the duty cycle observed in the afterglow may be understood. The reaction routes and rate coefficients for the production and of highly-excited molecular oxygen $O_{2}^{M}$ and $O_{2}^{*}\left(\mathrm{a}^{1} \Delta_{\mathrm{g}}\right)$ are given as,

$$
\begin{aligned}
& \mathrm{O}_{2}+\mathrm{e}^{-} \rightarrow O_{2}^{M}+\mathrm{e}^{-} \quad \mathrm{k}_{\mathrm{ex}}\left(\check{\mathrm{T}}_{\mathrm{e}}\right)=1.27 \times 10^{-8} \times \check{\mathrm{T}}_{\mathrm{e}}^{-0.52} \times \exp \left(-7.66 / \breve{\mathrm{T}}_{\mathrm{e}}\right) \mathrm{cm}^{3} \mathrm{~s}^{-1} \quad \text { [8] [26] } \\
& \mathrm{O}_{2}+\mathrm{e}^{-} \rightarrow O_{2}^{*}+\mathrm{e}^{-} \quad \mathrm{k}_{\mathrm{ex} 1}\left(\breve{\mathrm{T}}_{\mathrm{e}}\right)=1.7 \times 10^{-9} \times \exp \left(-3.1 / \breve{\mathrm{T}}_{\mathrm{e}}\right) \mathrm{cm}^{3} \mathrm{~s}^{-1}
\end{aligned}
$$

where $\breve{\mathrm{T}}_{\mathrm{e}}\left(=\mathrm{kT}_{\mathrm{e}}\right)$ is the electron temperature quoted in eV. In the on-time, $\mathrm{T}_{\mathrm{e}}$ is about $4-5 \mathrm{eV}$ so that $\mathrm{k}_{\mathrm{ex}}\left(\breve{\mathrm{T}}_{\mathrm{e}}=5 \mathrm{eV}\right)=1.2 \times 10^{-9} \mathrm{~cm}^{3} \mathrm{~s}^{-1}$ and $\mathrm{k}_{\mathrm{ex} 1}\left(\breve{\mathrm{T}}_{\mathrm{e}}=5 \mathrm{eV}\right)=1.2 \times 10^{-10} \mathrm{~cm}^{3} \mathrm{~s}^{-1}$. In the off-time when $\mathrm{T}_{\mathrm{e}}$ falls both these rate coefficients decrease rapidly and therefore the production of metastable $\mathrm{O}_{2}$ is considered only significant in the on-time. Although $O_{2}^{*}$ may be formed in the discharge, the rate coefficient for forming $\mathrm{O}^{-}$from $\mathrm{O}_{2}^{*}$ via dissociative attachment $\left(e^{-}+\mathrm{O}_{2}^{*} \rightarrow \mathrm{O}^{-}+O\right)$ reduces with decreasing $\mathrm{T}_{\mathrm{e}}$ and has a threshold of $3.75 \mathrm{eV}$ therefore, we consider only $\mathrm{O}_{2}^{M}$ as a candidate to create the negative ions we observe in the off-time via the reaction $e+O_{2}^{M} \rightarrow O^{-}+O$.

Since the temporal profiles of $T_{e}$ and $n_{e}$ are essentially independent of the off-time duration, but $n$. is highly modulated by it we argue that there must be different levels of $O_{2}^{M}$ in the discharge depending on the duty cycle. When the effective decay time $\tau$ of $O_{2}^{M}$ in the afterglow is shorter than the off-time duration $\mathrm{T}_{\text {off }}$, then little or no $\mathrm{O}_{2}^{M}$ is present at the beginning of the next cycle and the level of $O_{2}^{M}$ does not build up to high concentrations in the on-time. If $\tau>\mathrm{T}_{\text {off }}$ then the $O_{2}^{M}$ concentration may build up, leading to higher values and higher rates of rise of $\mathrm{n}_{\text {. }}$ The timeaveraged increase in $O_{2}^{M}$ concentration has already been modelled in [8]. The destruction of $O_{2}^{M}$ in the magnetron discharge at low pressure can come through a number of routes. These have already been stated with their associated rate coefficients for other similar pulsed plasmas. Using the same nomenclature as in [27] we have,

$$
\begin{array}{ll}
O_{2}^{M}+\mathrm{e}^{-} \rightarrow \mathrm{O}+\mathrm{O}+\mathrm{e}^{-} & \mathrm{k}_{\mathrm{diss}}\left(\check{\mathrm{T}}_{\mathrm{e}}\right)=8.95 \times 10^{-9} \times \check{\mathrm{T}}_{\mathrm{e}}^{-0.48} \exp \left(-4.32 / \check{\mathrm{T}}_{\mathrm{e}}\right) \mathrm{cm}^{3} \mathrm{~s}^{-1} \quad \text { [26] } \\
O_{2}^{M}+\mathrm{O}_{2} \rightarrow \mathrm{O}_{2}+\mathrm{O}_{2} & \mathrm{k}_{\mathrm{cr}}=2.8 \times 10^{-11} \mathrm{~cm}^{3} \mathrm{~s}^{-1}
\end{array}
$$




$$
\begin{array}{ll}
O_{2}^{M}+\mathrm{e}^{-} \rightarrow \mathrm{O}^{-}+\mathrm{O} & k_{a t}^{M}\left(\breve{\mathrm{T}}_{\mathrm{e}}\right)=-1.69 \times 10^{-12}+6.27 \times 10^{-10} / \breve{\mathrm{T}}_{\mathrm{e}}-1.30 \times 10^{-10} / \check{\mathrm{T}}_{\mathrm{e}}^{2}+9.60 \times \\
& 10^{-12} / \check{\mathrm{T}}_{\mathrm{e}}^{3} \mathrm{~cm}^{3} \mathrm{~s}^{-1}[26] \\
O_{2}^{M}+\mathrm{Ar}+\rightarrow \mathrm{O}_{2}+\mathrm{Ar} & \mathrm{k}_{\mathrm{ar}} \sim 1 \times 10^{-11} \mathrm{~cm}^{3} \mathrm{~s}^{-1}[28]
\end{array}
$$

A general balance equation can be written

$$
\frac{d n_{O_{2}^{M}}}{d t}=k_{e x} n_{O_{2}} n_{e}-\left(k_{d i s s} n_{e}+k_{c r} n_{O_{2}}+k_{a t}^{M} n_{e}+k_{A r} n_{A r}+\frac{1}{\tau_{L}}\right) n_{O_{2}^{M}}
$$

Where $\tau_{\mathrm{L}}$ is the effective time-constant from diffusional (wall) loses. Assuming most metastables are not reflected at the walls (reaction probability $\gamma$ close to unity) $\tau_{\mathrm{L}}$ is $\sim \mathrm{R} / \mathrm{v}_{\text {th }}$ where $\mathrm{R}(\sim 0.05 \mathrm{~m})$ is the plasma radius and $\mathrm{v}_{\text {th }}\left(\sim 280 \mathrm{~ms}^{-1}\right)$ is the $\mathrm{O}_{2}$ thermal velocity yielding $\tau_{\mathrm{L}} \sim 180 \mu \mathrm{s}$. In the rate equation the $k_{A r}$ term representing the destruction of the metastable state through collision with the noble gas is somewhat uncertain [28] and we have estimated it to be $\sim 1 \times 10^{-11} \mathrm{~cm}^{3} \mathrm{~s}^{-1}$ based on the $O_{2}^{M}$ being in high vibrational states $(v=5,7,9)$.

In the off-time, we can estimate an average value for each term on the RHS of the above equation and an overall $O_{2}^{M}$ decay-time $\tau_{O_{2}^{M}}$. In the off-time, the dominant terms are $k_{c r} n_{O_{2}}$ and $k_{A r} n_{A r}$ and averaging over the afterglow period yields characteristic decay times of $\tau_{O_{2}^{M}}=\left(k_{c r} n_{O_{2}}+k_{A r} n_{A r}\right)^{-1} \sim$ 256 and $163 \mu \mathrm{s}$ for $\mathrm{P}_{\mathrm{O} 2} / \mathrm{P}_{\mathrm{O} 2+\mathrm{Ar}}=0.1$ and 0.5 respectively. These values are in the right range to allow the modulation of the density of $\mathrm{O}_{2}^{M}$ due to different off-time durations, with shorter decays at the higher $\mathrm{O}_{2}$ concentration $\left(\mathrm{P}_{\mathrm{O} 2} / \mathrm{P}_{\mathrm{O} 2+\mathrm{Ar}}=0.5\right)$. These values are about the same size as the estimated diffusional lose-time of $\tau_{\mathrm{L}} \sim 180 \mu \mathrm{s}$, however this latter figure assumes the loss coefficient $\gamma$ (reaction probability) of matastable molecules at the walls is close to unit. Panda et al [8] argue that $\gamma$ for $O_{2}^{M}$ is close to that for $O_{2}^{*}$ at $\sim 10^{-5}$ and therefore $\tau_{\mathrm{L}}$ may be much longer.

Another way to modulate the density of $O_{2}^{M}$ is through variation of the target reaction probability of the metastable with the surface due to poisoning by oxygen in the off-time and sputter cleaning of the racetrack region in the on-time. Since the target is not an insignificant fraction of the wall area, varying the off-times (and hence target condition) could affect the time-average concentrations of $\mathrm{O}_{2}^{M}$ and also $\mathrm{O}$ (as argued in [8]). Some other destruction reactions are also feasible for instance, in the on-time when the target is sputtered we could consider $O_{2}^{M}+\mathrm{Ti}+\rightarrow \mathrm{O}_{2}+\mathrm{Ti}$, however the rate coefficient is unknown by the authors. This reaction may even be important in the off-time 
since it has been shown that $\mathrm{Ti}$ atoms can reside in the afterglow at positions a few cm's from the target for times up to milliseconds [29].

So we argue that shorter off-times lead to higher $O_{2}^{M}$ concentrations in the discharge over the whole cycle, and can lead to faster rates of rise of $\mathrm{O}^{-}$in the off-time as the duty cycle is reduced through the production mechanism $O_{2}^{M}+\mathrm{e}^{-} \rightarrow \mathrm{O}^{-}+\mathrm{O}$ with rate coefficient $k_{a t}^{M}\left(T_{e}\right)$.

The main production and loss channels (and associated rate coefficients) for $\mathrm{O}^{-}$are

$$
\begin{array}{ll}
O_{2}^{M}+\mathrm{e}^{-} \rightarrow \mathrm{O}^{-}+\mathrm{O} & k_{a t}^{M}\left(\breve{\mathrm{T}}_{\mathrm{e}}\right)=-1.69 \times 10^{-12}+6.27 \times 10^{-10} / \breve{\mathrm{T}}_{\mathrm{e}}-1.30 \times 10^{-10} / \breve{\mathrm{T}}_{\mathrm{e}}^{2}+9.60 \times \\
\mathrm{O}^{-}+\mathrm{O}^{+} \rightarrow \mathrm{O}+O^{*} & 10^{-12} / \check{\mathrm{T}}_{\mathrm{e}}^{3}[26] \\
\mathrm{O}^{-}+\mathrm{e}^{-} \rightarrow \mathrm{O}+2 \mathrm{e}^{-} & k_{m n}^{O+}=2 \times 10^{-7}\left(300 / \mathrm{T}_{\mathrm{g}}\right)^{0.5} \mathrm{~cm}^{3} \mathrm{~s}^{-1} \quad\left(\mathrm{~T}_{\mathrm{g}} \text { is the gas temperature }\right)[8] \\
\mathrm{O}^{-}+O_{2}^{+} \rightarrow \mathrm{O}+O_{2}^{*} & \mathrm{k}_{\mathrm{ed}}\left(\breve{\mathrm{T}}_{\mathrm{e}}\right)=2 \times 10^{-7} \exp \left(-5.5 / \breve{\mathrm{T}}_{\mathrm{e}}\right) \mathrm{cm}^{3} \mathrm{~s}^{-1}[8][26] \\
\mathrm{O}^{-}+\mathrm{O} \rightarrow \mathrm{O}_{2}+\mathrm{e}^{-} & k_{m n}^{O_{2}+}=1 \times 10^{-7} \mathrm{~cm}^{3} \mathrm{~s}^{-1}[26] \\
\mathrm{O}^{-}+\mathrm{Ar}^{+} \rightarrow \mathrm{O}+\mathrm{Ar} & \mathrm{k}_{\mathrm{ad}}=1.4 \times 10^{-10} \mathrm{~cm}^{3} \mathrm{~s}^{-1}[27] \\
\mathrm{O}^{-}+O_{2}^{*} \rightarrow \mathrm{O}_{3}+\mathrm{e}^{-} & \mathrm{k}_{\mathrm{ar}}=1.4 \times 10^{-7} \mathrm{~cm}^{3} \mathrm{~s}^{-1}[26] \\
\mathrm{O}^{-}+O_{2}^{*} \rightarrow O_{2}^{-}+\mathrm{O} & \mathrm{k}_{02}=3 \times 10^{-10} \mathrm{~cm}^{3} \mathrm{~s}^{-1}[8] \\
& k_{O 2}^{1}=1 \times 10^{-10} \mathrm{~cm}^{3} \mathrm{~s}^{-1}[26]
\end{array}
$$

A rate balance equation can be written

$$
\frac{d n_{O^{-}}}{d t}=k_{a t}^{M} n_{e} n_{O_{2}^{M}}-n_{O^{-}}\left(k_{e d} n_{e}+k_{m n}^{O+} n_{O^{+}}+k_{m n}^{O_{2}+} n_{O_{2}{ }^{+}}+k_{a d} n_{O}+k_{A r} n_{A r}+k_{o 2} n_{O_{2}}+k_{O 2}^{1} n_{O_{2}}+\frac{1}{\tau_{A D}}\right)
$$

Where $\tau_{\mathrm{AD}}$ is the ambipolar diffusion loss-time of $\mathrm{O}^{-}$to the walls. The initial rise in the off-time can be described by

$$
\frac{d n_{O^{-}}}{d t} \approx k_{a t}^{M} n_{e} n_{O_{2}^{M}}
$$

So we have faster rate rises of $\mathrm{O}^{-}$with higher $\mathrm{O}_{2}^{M}$ concentrations in the off-time. Looking at the data for $\frac{d n_{O^{-}}}{d t}$ in figure $6\left(\mathrm{P}_{\mathrm{O} 2} / \mathrm{P}_{\mathrm{O} 2+\mathrm{Ar}}=0.1\right)$, and using the above equation the initial $O_{2}^{M}$ 
concentrations $n_{O_{2}^{M}}$ would have to be, $6.7 \times 10^{12}, 1.9 \times 10^{12}, 1.34 \times 10^{12}$ and $0.67 \times 10^{12} \mathrm{~cm}^{3}$ for 50 , 25, 12.5 and $5 \%$ duty cycles respectively. These are, 20, 5.7, 4.0 and $2 \%$ of the $\mathrm{O}_{2}$ density. From the $\mathrm{O}^{-}$data for $\mathrm{P}_{\mathrm{O} 2} / \mathrm{P}_{\mathrm{O} 2+\mathrm{Ar}}=0.5$ (figure 10), we calculate $n_{O_{2}^{M}}$ as $4,2.5,2$ and $1.6 \%$ of the $\mathrm{O}_{2}$ concentration. These percentages are within a factor 2 of those calculated for the lower $\mathrm{O}_{2}$ level case above, and fall progressively in the same manner.

From figures 6 and 10 it can be observed that in the long off-time the $\mathrm{O}^{-}$concentration falls and this can be described by the equation $\frac{d n_{O^{-}}}{d t} \approx-\frac{n_{O^{-}}}{\tau_{O^{-}}}$. Experimentally, the decay times for $\tau_{O^{-}}$are $\sim 275$ and $\sim 200 \mu \mathrm{s}$ for the $\mathrm{P}_{\mathrm{O} 2} / \mathrm{P}_{\mathrm{O} 2+\mathrm{Ar}}=0.1$ and 0.5 cases respectively (as see in figures 6 and 10). Assuming $\tau_{\mathrm{AD}}$ is long, a calculation of the effective decay time using average plasma and operating parameters gives $\tau_{O^{-}} \sim 390 \mu \mathrm{s}$ and $\sim 234 \mu \mathrm{s}$ for $\mathrm{P}_{\mathrm{O} 2} / \mathrm{P}_{\mathrm{O} 2+\mathrm{Ar}}=0.1$ and 0.5 respectively. These rates are roughly in line with the measured long-term n. decay rates, and predict that the decay rates shortens with increased $\mathrm{O}_{2}$ content as experimentally observed.

In reference [8], it was shown through modelling that the $\mathrm{O}^{-}$densities are particularly sensitive to discharge power with $n$. reducing by a factor of 4 on average over the pulse cycle as the power was increased from 150 to $500 \mathrm{~W}$. This was attributed to more dissociation of $\mathrm{O}_{2}$ as the electron density increasing so reducing the $\mathrm{O}_{2}^{M}$ concentration. We expect a similar scaling in the magnetron discharge, and future studies will investigate high powers more consistent with industrial sputterdeposition applications.

\section{Conclusions}

Using laser photodetachment and Langmuir probing the $\mathrm{O}^{-}$density in a low-power pulsed DC magnetron with a titanium target has been determined as a function of time during the pulse period for a number of different off-times. The oxygen partial pressure was fixed at either 10 or $50 \%$ of the total pressure of 1.3 Pa. The results show in the discharge on-time the plasma is weakly electronegative with $\alpha\left(\mathrm{O}^{-}\right.$to electron density ratio) values typically between 0.1 and 0.6 . However, in the off-time the negative ion density increases sharply as a function of time at rates which increase with reduced duty cycles. In the afterglow, the plasma is highly electronegative with $\alpha$ reaching 4.6 and 14.4 for the 10 and $50 \%$ oxygen partial pressure cases respectively. For long off- 
times, the negative ion density begins to fall after $500 \mu \mathrm{s}$ and $200 \mu \mathrm{s}$ (for 10 and $50 \% \mathrm{O}_{2}$ content) with characteristic decay times of several 100's of $\mu$ s, shortening with increased $\mathrm{O}_{2}$ content. The rise in $\mathrm{O}^{-}$density in the off-time, when the electron temperature rapidly falls, is attributed to the production of highly excited matastable oxygen molecules created largely in the on-time, which subsequently undergo dissociate electron attachment. A comparison has been made between the photodetachment measurements of negative ion density and these obtained directly from the Langmuir probe characteristics using plasma boundary theory for electronegative discharges. In the high $\alpha$ regime, the results agree to within a factor ranging from 2 to 5 , showing the applicability of Langmuir probes in highly electronegative plasmas to determine negative ion densities. Future investigations will concentrate on the effect of discharge power on the $\mathrm{O}^{-}$densities in the pulse magnetron, with relevance to high-power thin film deposition discharges.

Acknowledgements. The authors wish to thanks the EPSRC for their funding support. 


\section{References}

1] Mráz S and Schneider JM, Plasma Chem. Plasma Proc. 262 (2006)197

2] Mráz S and Schneider JM, Appl. Phys. Lett. 89 (2006) 051502

3] Mráz S and Schneider JM, J. Appl. Phys. 100 (2006) 023503

4] Mišina M, Bradley JW, Bäcker H, Aranda-Gonzalvo Y, Karkari SK and Forder D, Vacuum 68 (2003) 171

5] Mahieu S and Depla Dl, Appl. Phys. Lett. 90 (2007) 121117

6] Mahieu S, Leroy WP, Van Aeken K and Depla D, J. Appl. Phys. 106 (2009) 093302

7] Bultinck, E and Bogaerts, A, New J. of Phys. 11 (2009) 103010

8] Panda S, Economou D J and Meyyappan M J. Appl. Phys. 8712 (2000) 8323

9] Straňák V, Blažek J, Wrehde S, Adámek P, Hubička Z, Tichý M, Špatenka P and Hippler R Contrib. Plasma Phys. 48 (2008) 503

10] Dodd R, You SD, Bryant P and Bradley JW, Plasma Sources Sci. Technol. 19 (2010) 015021

11] Dodd, You SD, and Bradley JW, ' $\mathrm{O}^{-}$density measurements in the pulsed-dc reactive magnetron sputtering of titanium', Thin Solid Films (2010), in print.

12] Rack PD, Potter MD, Woodard A and Kurinec S, J. Vac. Sci. Technol. A 17 (1999) 2805

13] Rieth LW and Holloway PH, J. Vac. Sci. Technol. A 22 (2004) 20

14] Tominga K, Chong M and Shintani Y, J. Vac. Sci. Technol. A 12 (1994) 1435

15] Kim SM, Rim YS, Keum MJ and Kim KH, J. Electroceramics 23 2-4 (2009) 341

16] Michikami O and Asahi M, Jap. J. Appl. Phys. 130 (1991) 5

17] Braithwaite N st J and Allen JE. J. Phys. D: Appl. Phys. 21 (1988) 1733

18] Kajita S, Kado S and Tanaka S 2005 Plasma Sources Sci. Technol. 14566

19] Bacal M, Rev Sci. Instrum. 7111 (2000) 3981

20] Lieberman MA and Ashida S, Plasma Sources Sci. Technol. 5 (1996) 145

21] Ding WX, Pinnaduwage LA, Tav C and McCorkle DL, Plasma Sources Sci. Technol. 8 (1999) 384

22] Nikitin AG, El Balghiti F and Bacal M, Plasma Sources Sci. Technol. 5 (1996) 37

23] Linss V, Spectro. ACTA B 602 (2005) 253

24] Kolev I and Bogaerts A, J. Appl. Phys. 104, (2008) 093301

25] Sheridan TE, Chabert P and Boswell RW, Plasma Sources Sci. Technol. 8 (1999) 457

26] Wagner JA and Katsch H-M, Plasma Source Sci. Technol. 15 (2006) 156

27] Hayashi and Kadota, Jpn. J Appl. Phy. 371 1A (1999) 225

28] Knutsen K, Dyer MJ and Copeland RA, J. Chem Phys. 1019 (1994) 7415

29] Sasaki K, Nafarizal N,Gao J-S, Shibagaki K, Vacuum 83 (2009) 463 


\section{Figure Captions}

Figure 1. A schematic diagram of the experimental set-up. Key: M1 and M2 - turning mirrors, VA - variable aperture, BW - blocking wire BS - beam splitter, PM - power meter, PD - photodiode, W1 and W2 - windows, LBA - laser beam analyser, MFC1 and MFC2 - mass flow controllers, C $=1 \mu \mathrm{F}, \mathrm{C}_{\mathrm{bp}}=1000 \mu \mathrm{F}, \mathrm{R} 1=47 \Omega, \mathrm{R} 2=4.7 \mathrm{k} \Omega$ and $\mathrm{LP}-$ Langmuir probe.

Figure 2. The magnetic field geometry (measured by a Hall probe) together with the Langmuir probe position and laser beam line-of-sight.

Figure 3. The discharge current and voltage waveforms and the derived instantaneous discharge power for a) the $50 \%$ duty cycle and b) $5 \%$ duty cycle. The $\mathrm{O}_{2}$ partial pressure is $10 \%$.

Figure 4. The temporal evolution of electron density for the four chosen duty cycles and for $10 \%$ $\mathrm{O}_{2}$ partial pressure. The inserted plot shows the relationship between electron density and the evolving applied power.

Figure 5. The temporal evolution of electron temperature for the four chosen duty cycles and for 10 $\% \mathrm{O}_{2}$ partial pressure.

Figure 6. The temporal evolution of negative ion $\left(\mathrm{O}^{-}\right)$density for the four chosen duty cycles and for $10 \% \mathrm{O}_{2}$ partial pressure.

Figure 7. The temporal evolution of the negative ion-to-electron density ratio for the four chosen duty cycles and for $10 \% \mathrm{O}_{2}$ partial pressure.

Figure 8. The temporal evolution of electron density for the four chosen duty cycles and for $50 \%$ $\mathrm{O}_{2}$ partial pressure. The inserted plot shows the relationship between electron density and the evolving applied power.

Figure 9. The temporal evolution of electron temperature for the four chosen duty cycles and for 50 $\% \mathrm{O}_{2}$ partial pressure.

Figure 10. The temporal evolution of negative ion $\left(\mathrm{O}^{-}\right)$density for the four chosen duty cycles and for $50 \% \mathrm{O}_{2}$ partial pressure. 
Figure 11. The temporal evolution of the negative ion-to-electron density ratio for the four chosen duty cycles and for $10 \% \mathrm{O}_{2}$ partial pressure.

Figure 12. A set of example Langmuir probe characteristics (in the on-time, $t=10,20,30,40,50$ $\mu \mathrm{s}$, and the off-time $\mathrm{t}=55,200,500,850,980 \mu \mathrm{s})$ split into electron and ion saturation current parts for the case of $5 \%$ duty cycle and $\mathrm{P}_{\mathrm{O} 2} / \mathrm{P}_{\mathrm{O} 2+\mathrm{Ar}}=0.5$.

Figure 13. The plot of the theoretical normalised electron-to-ion saturation current ratio versus the negative ion-to-electron density ratio, taken from a particle model in spherical geometry [17] and a fluid model in planar geometry [25], with $\gamma=\mathrm{T}_{\mathrm{e}} / \mathrm{T}_{-}=5$. The solution for $\gamma=1$, which requires no modification of the Bohm criterion and is valid in either model is also plotted.

Figure 14. A plot of the values of $\alpha$ determined directly from the Langmuir probe data using a model for the Bohm current described above (with $\gamma=\mathrm{T}_{\mathrm{e}} / \mathrm{T}_{-}=1$ and 5) against those measured by the photodetached technique for the particular case of $5 \%$ duty cycle and 10 and $50 \% \mathrm{O}_{2}$ partial pressure. The solid line denotes where these quantities would be equal. 
Figures

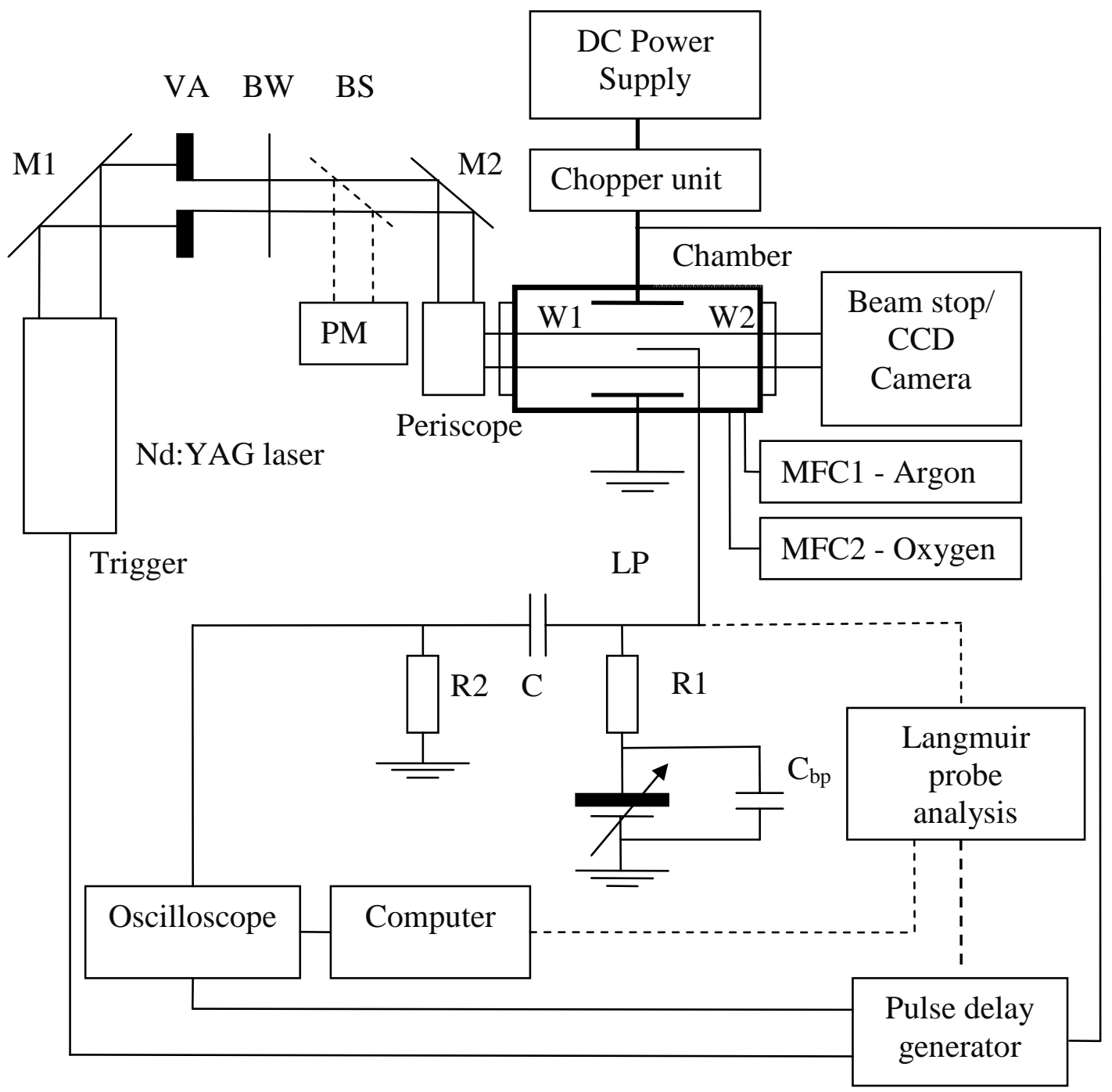

Figure 1 


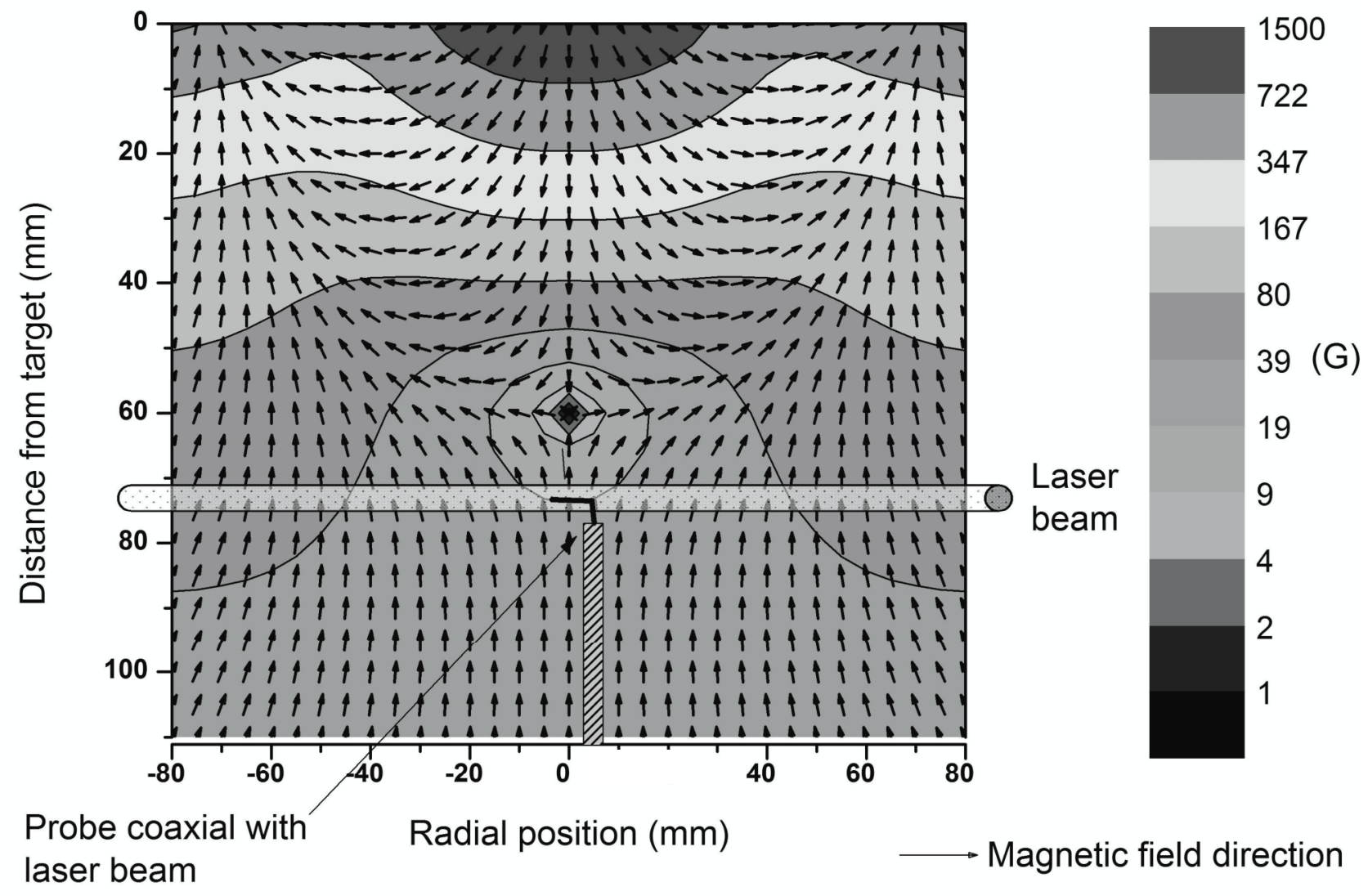

Figure 2 


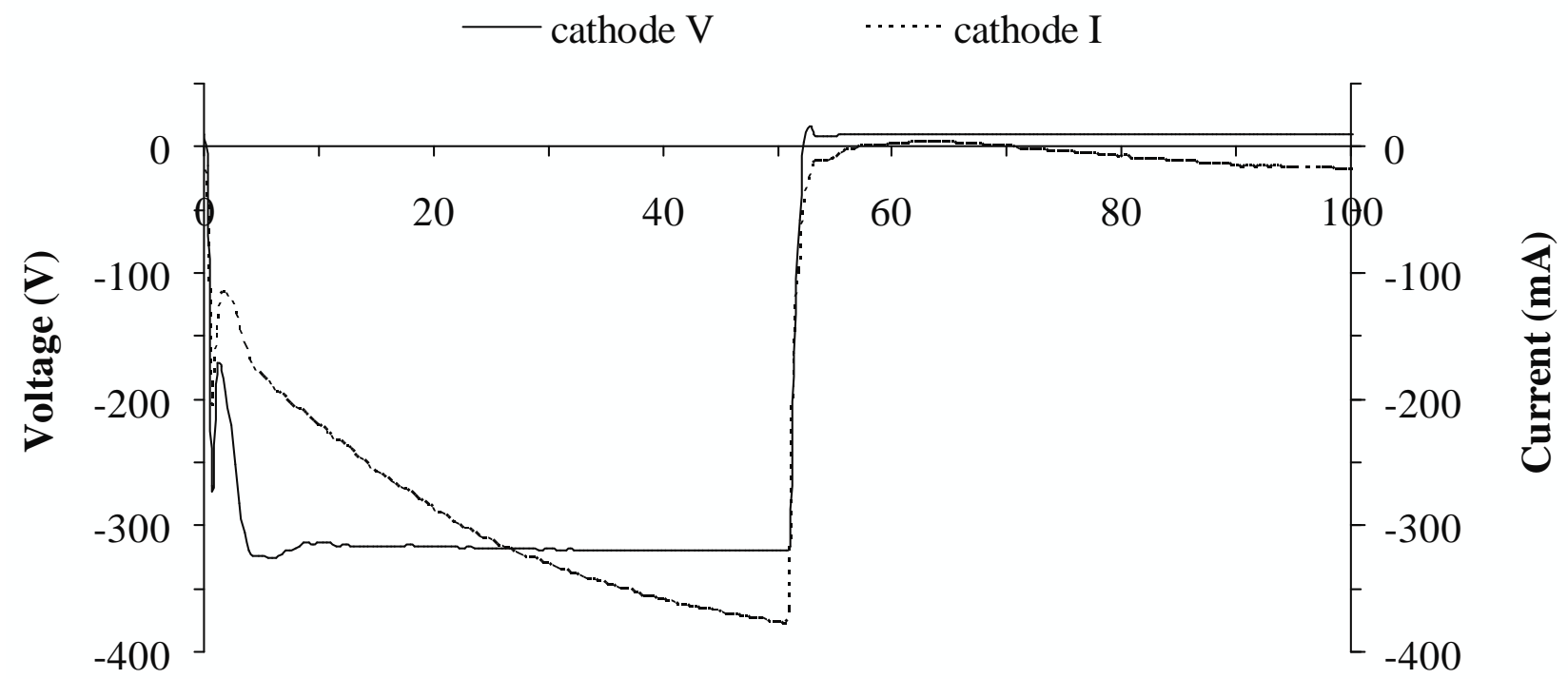

Time ( $\mu s)$

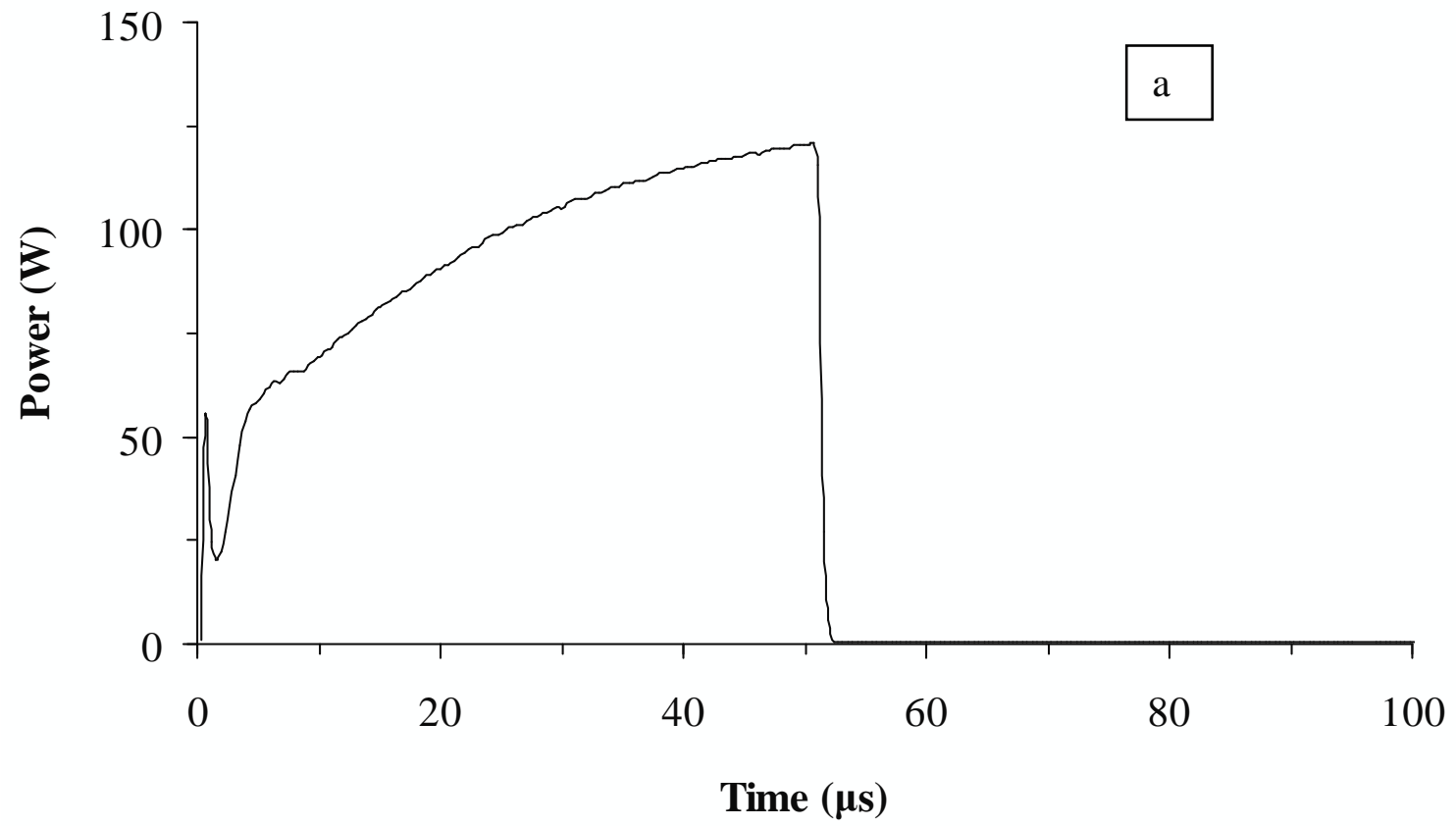

Figure $3 \mathrm{a}$ 


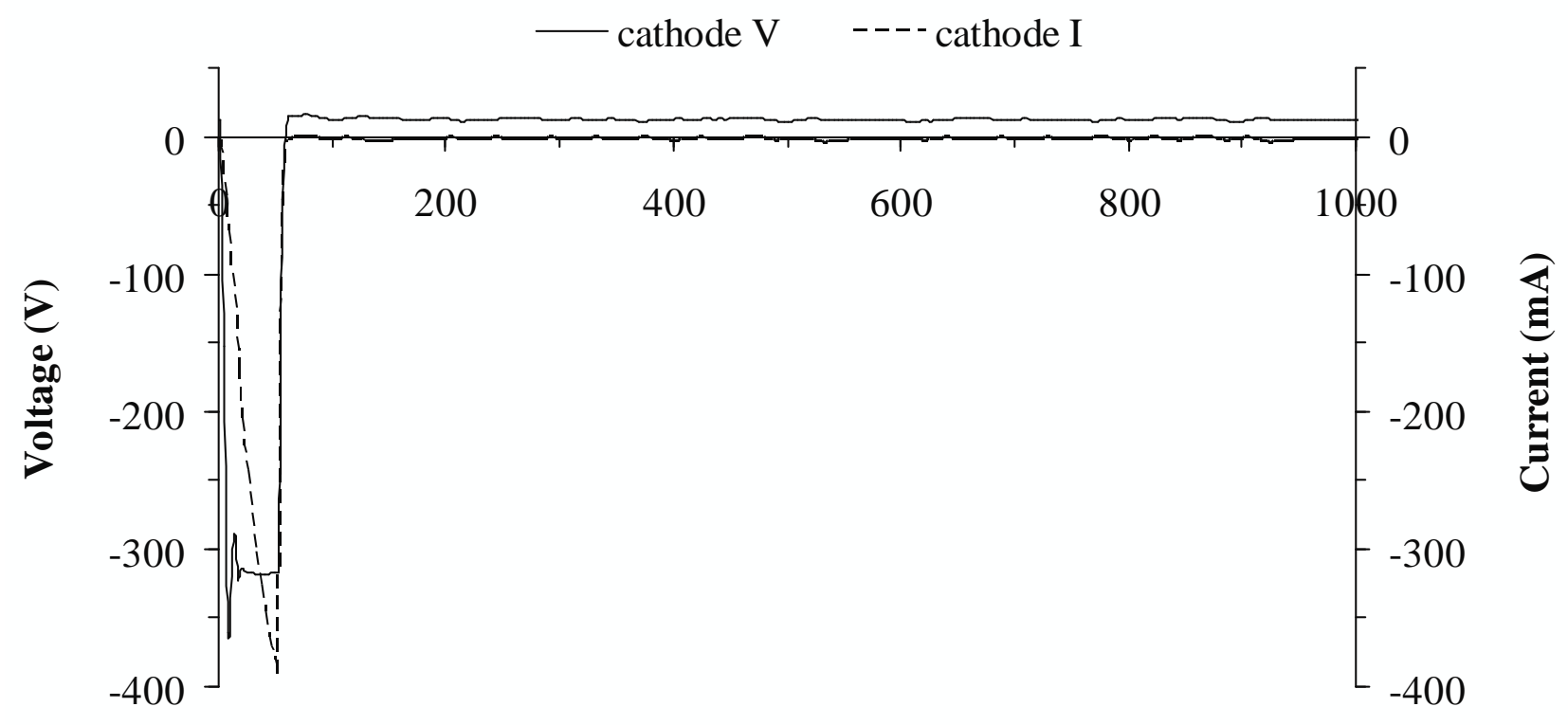

Time $(\mu s)$

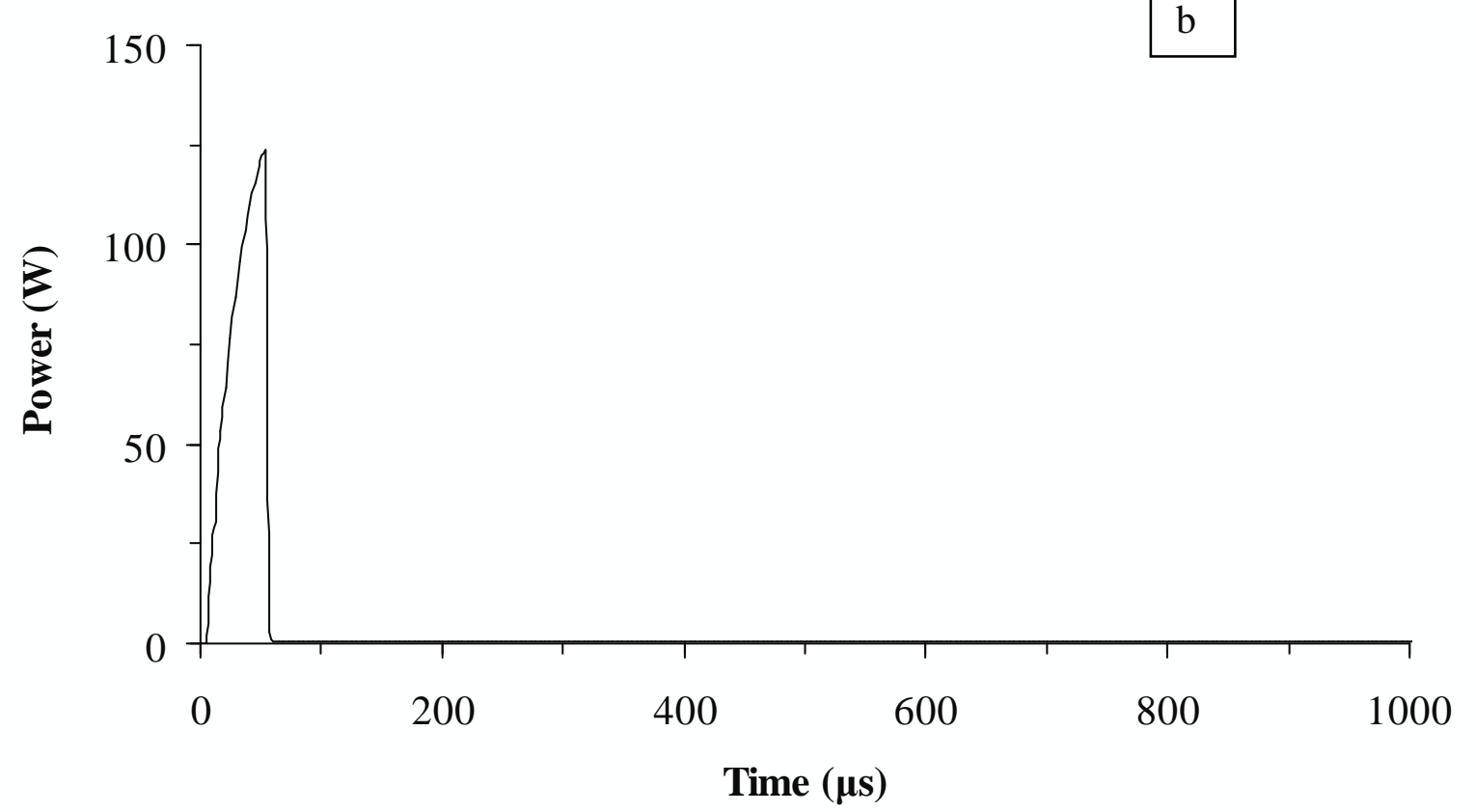

Figure $3 b$ 


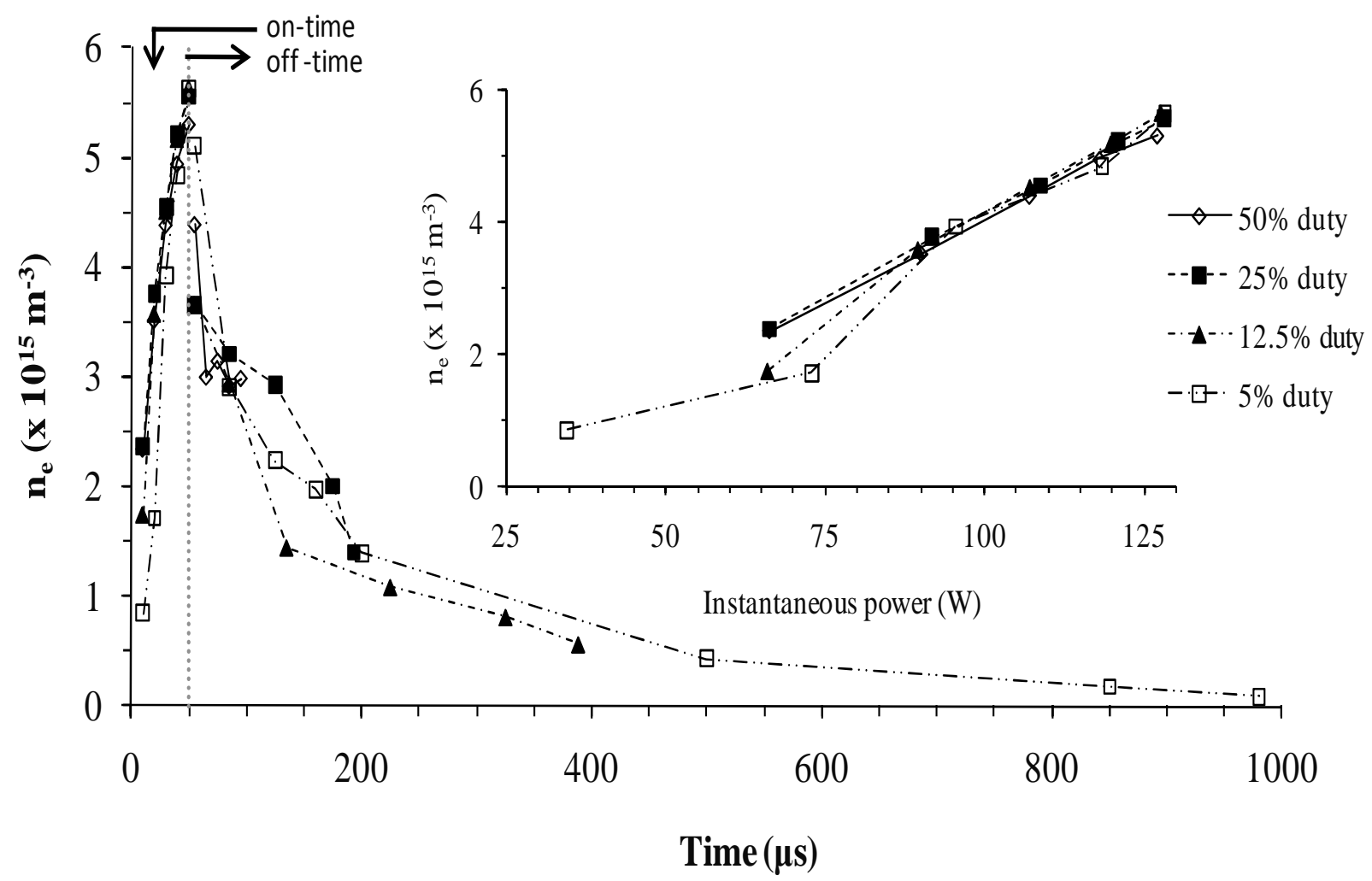

Figure 4 


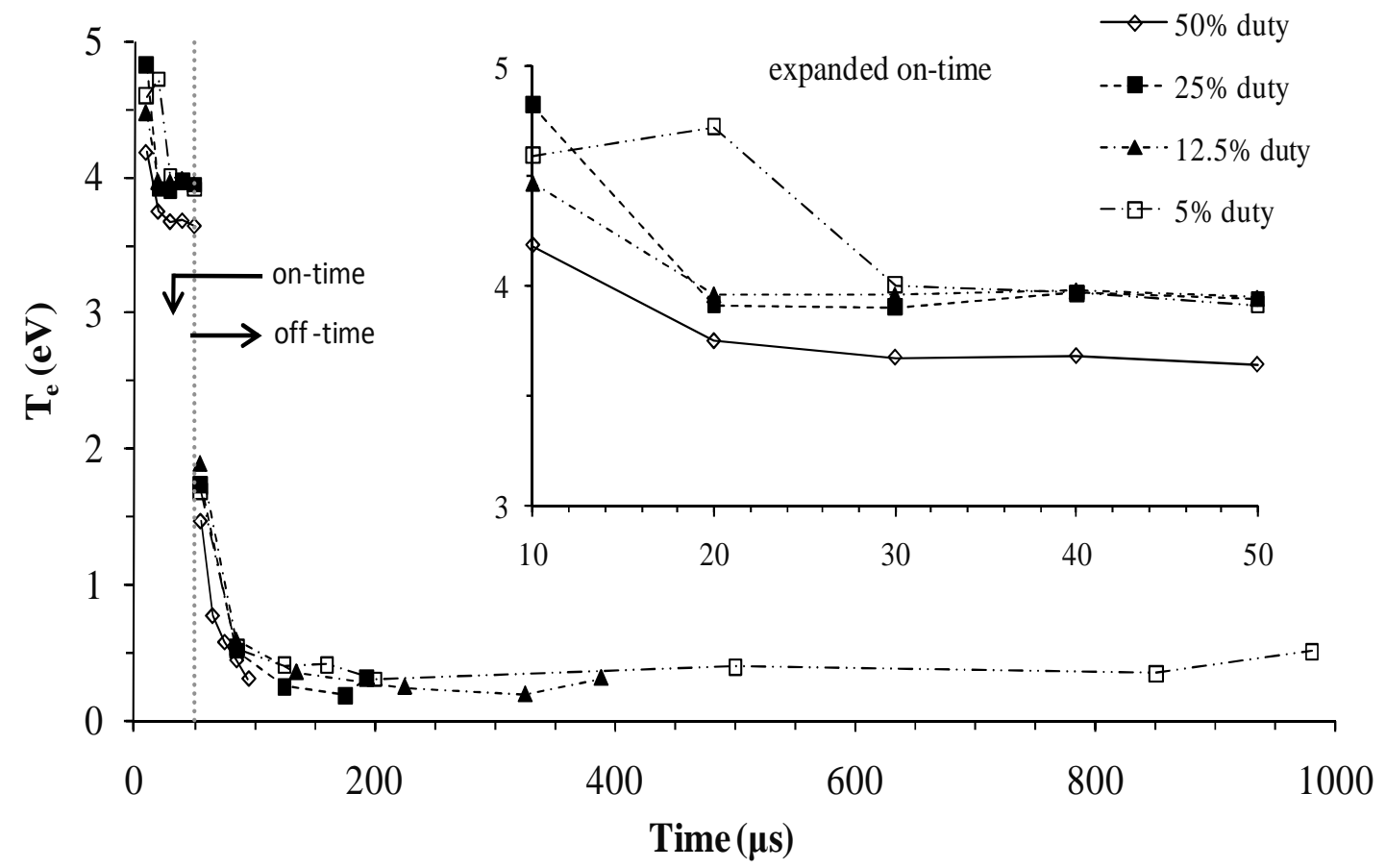

Figure 5 


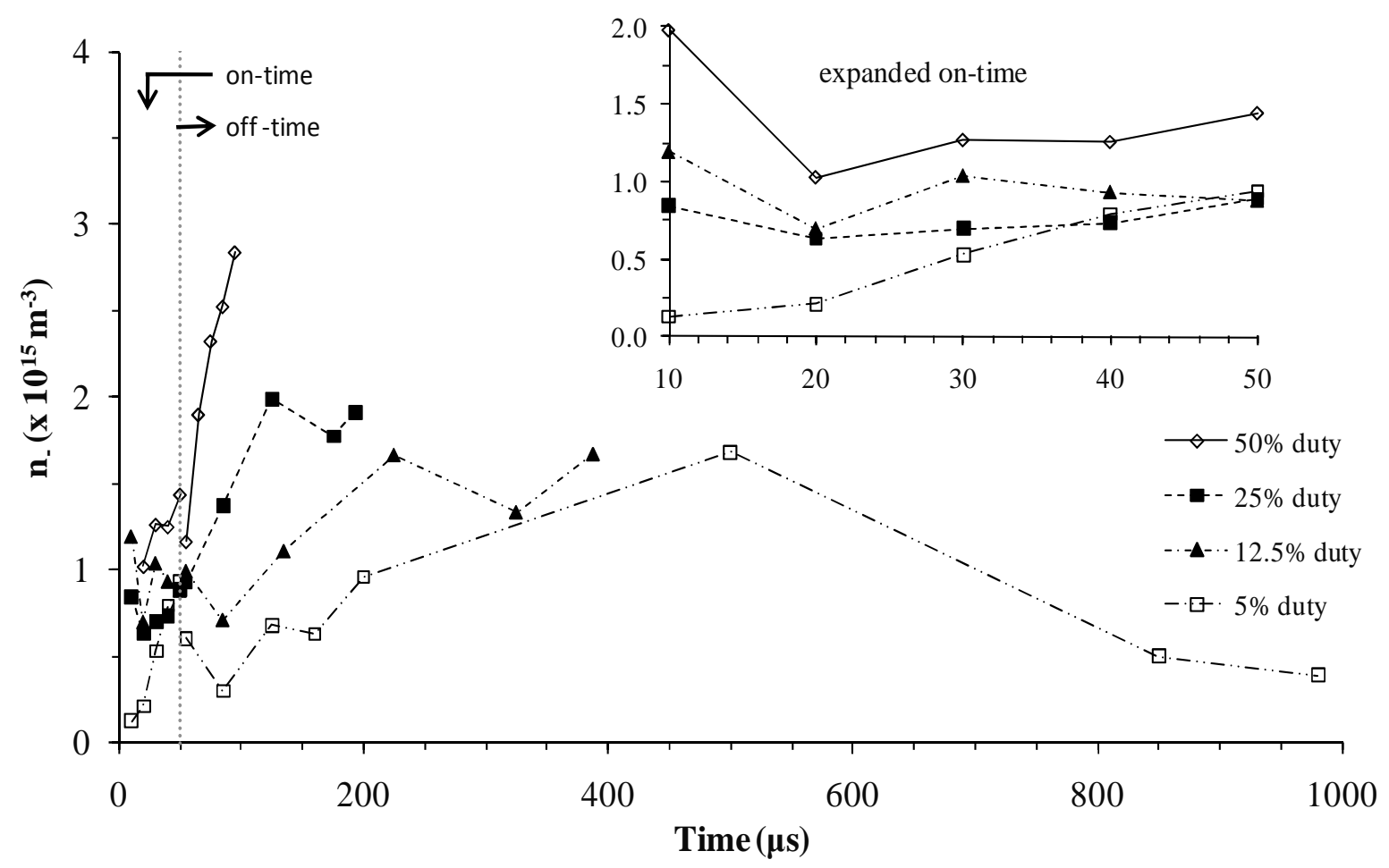

Figure 6 


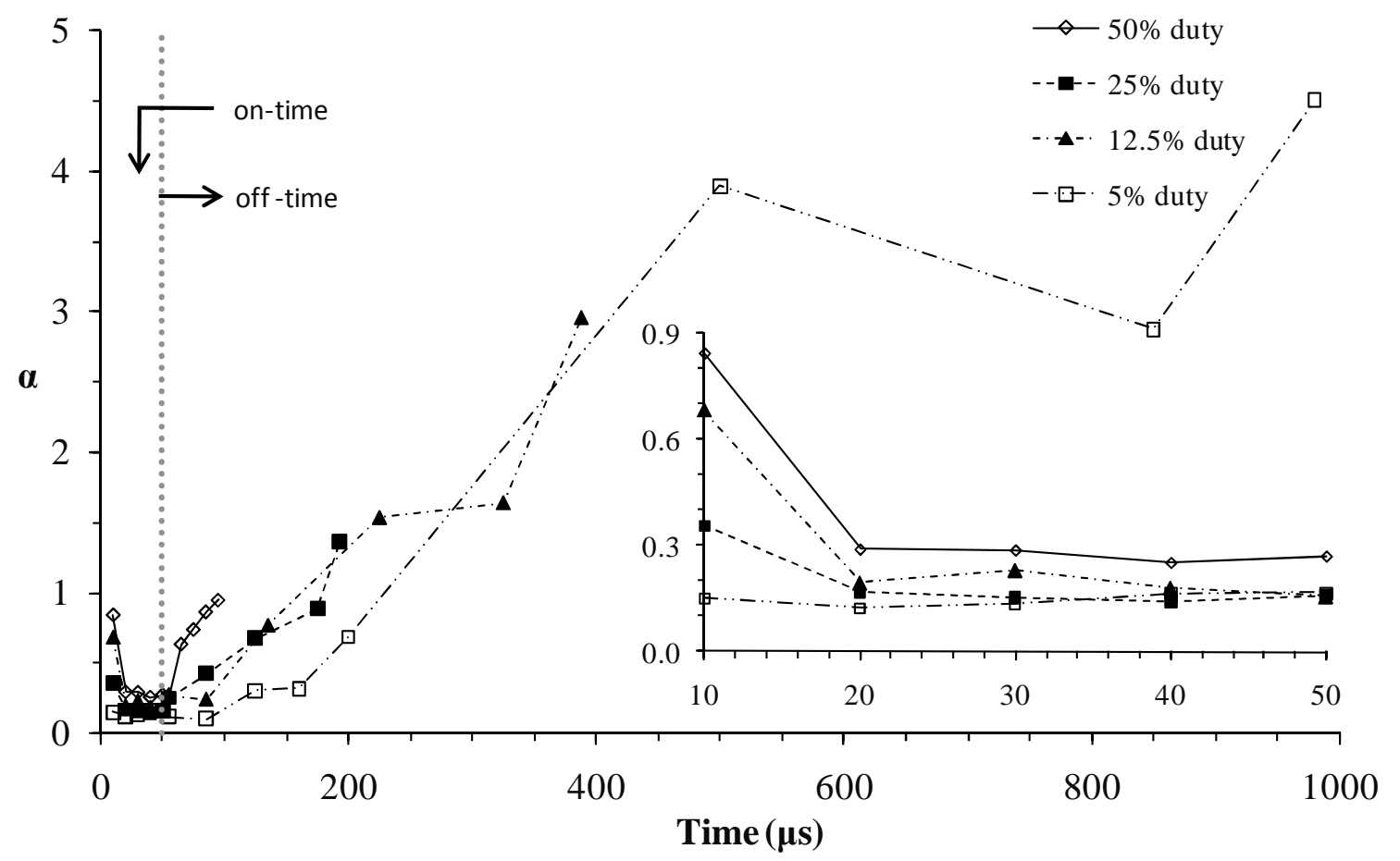

Figure 7 


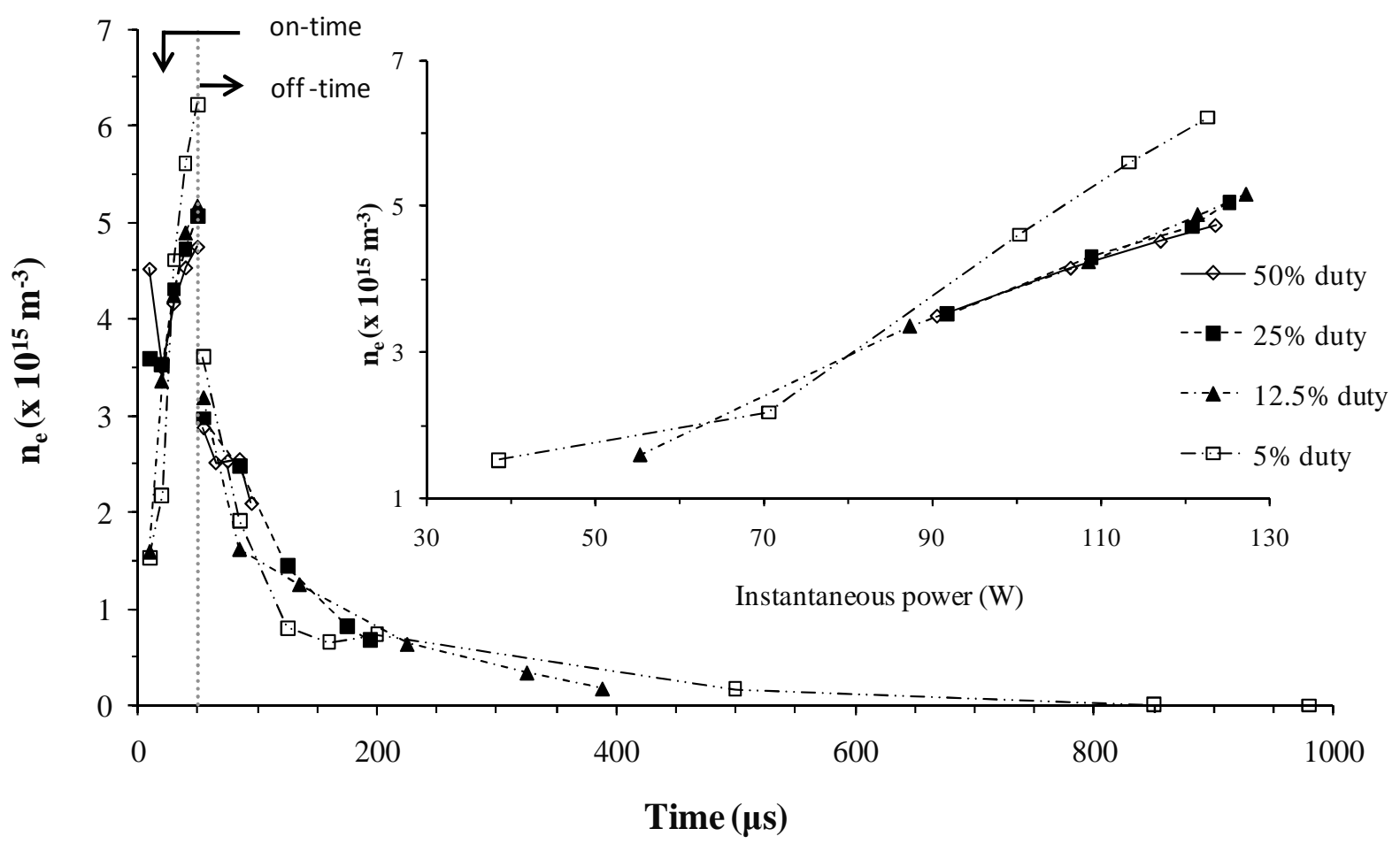

Figure 8 


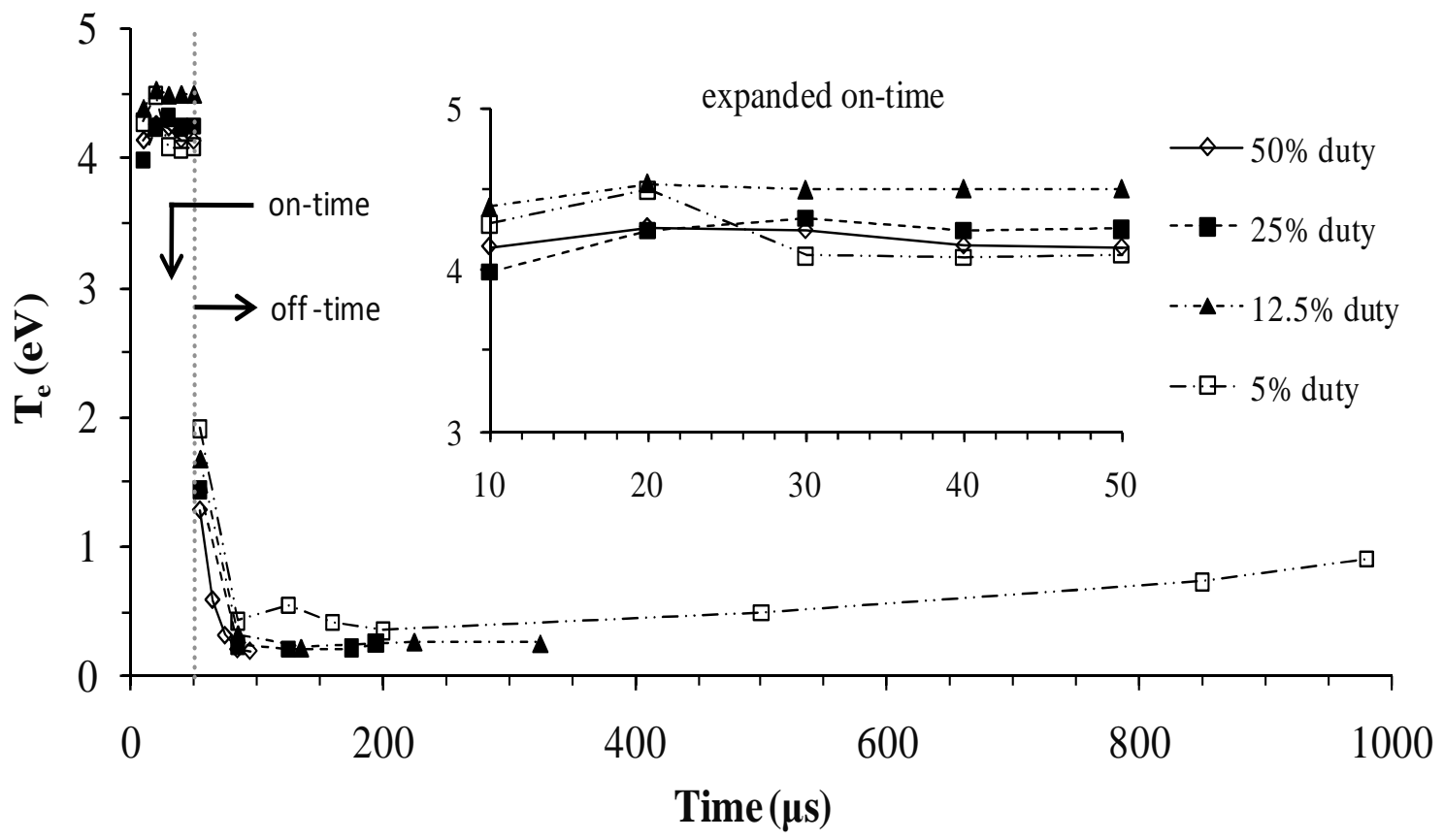

Figure 9 


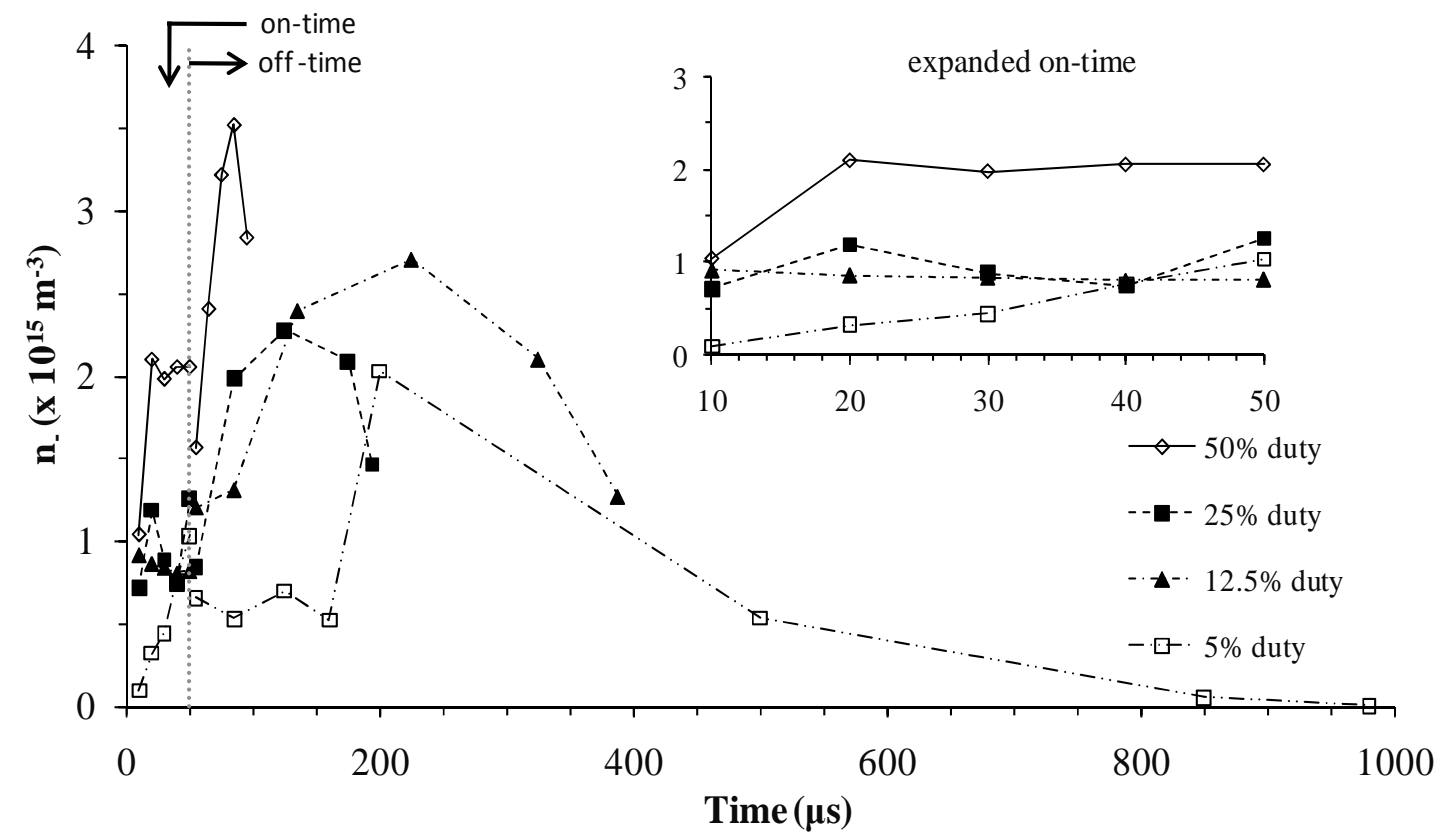

Figure 10 


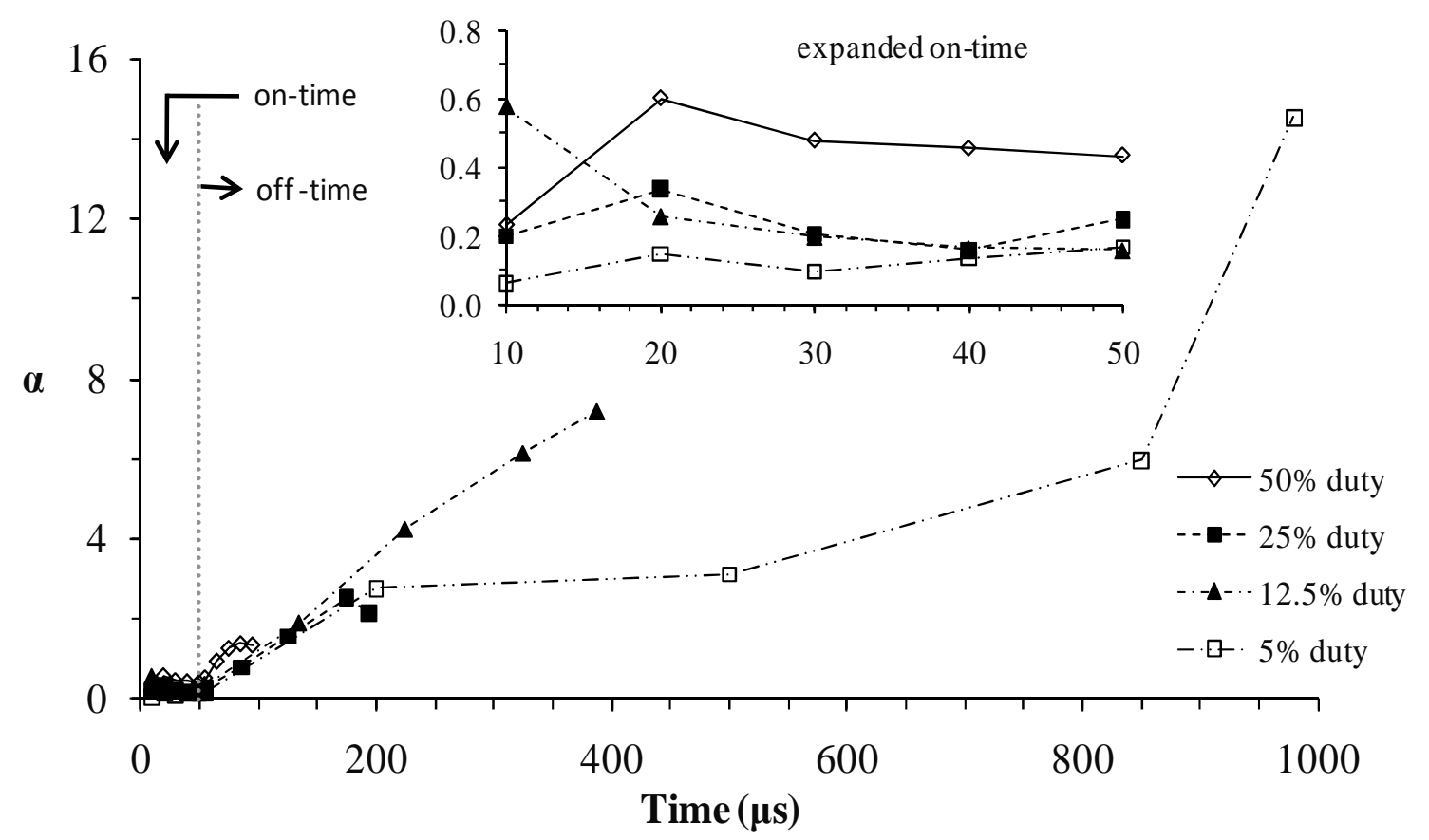

Figure 11 


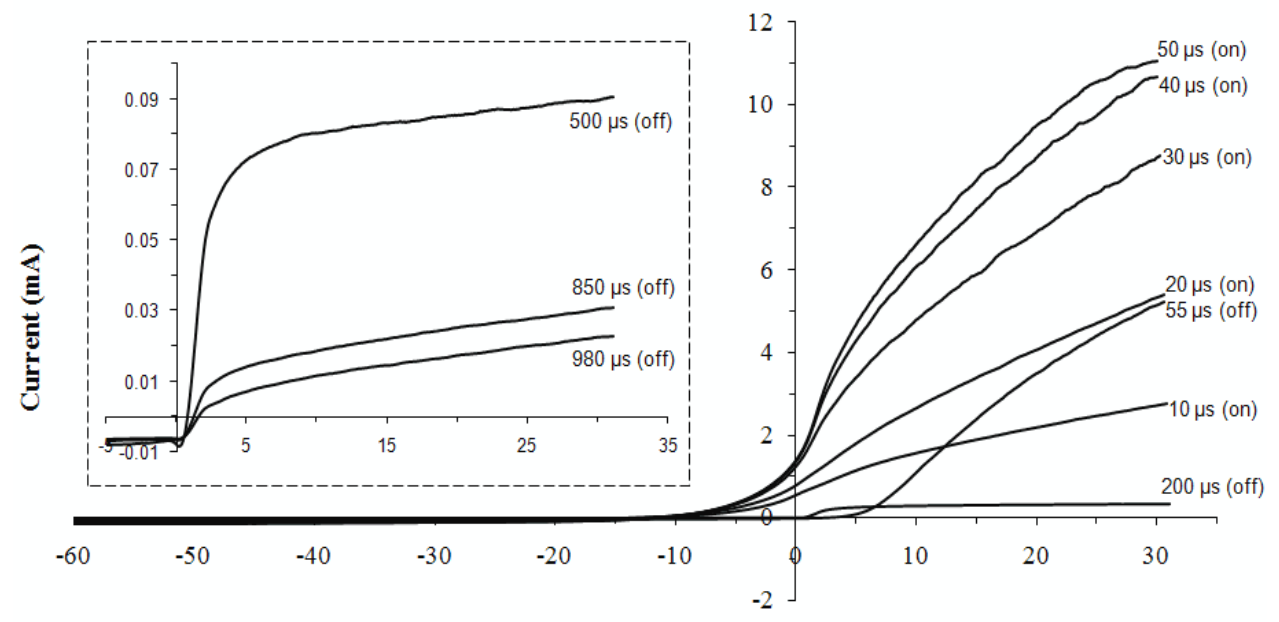

Voltage (V)
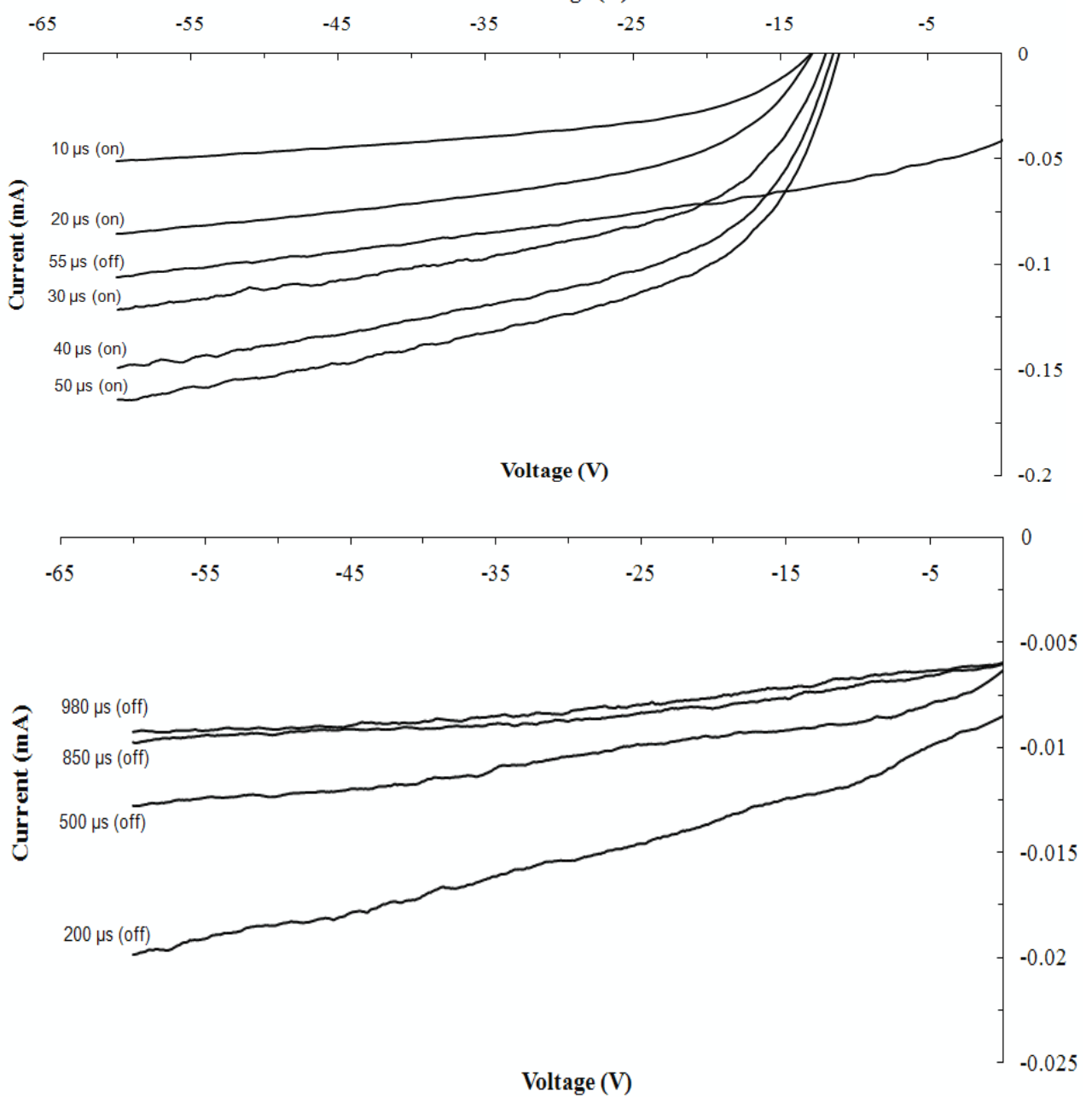

Figure 12 


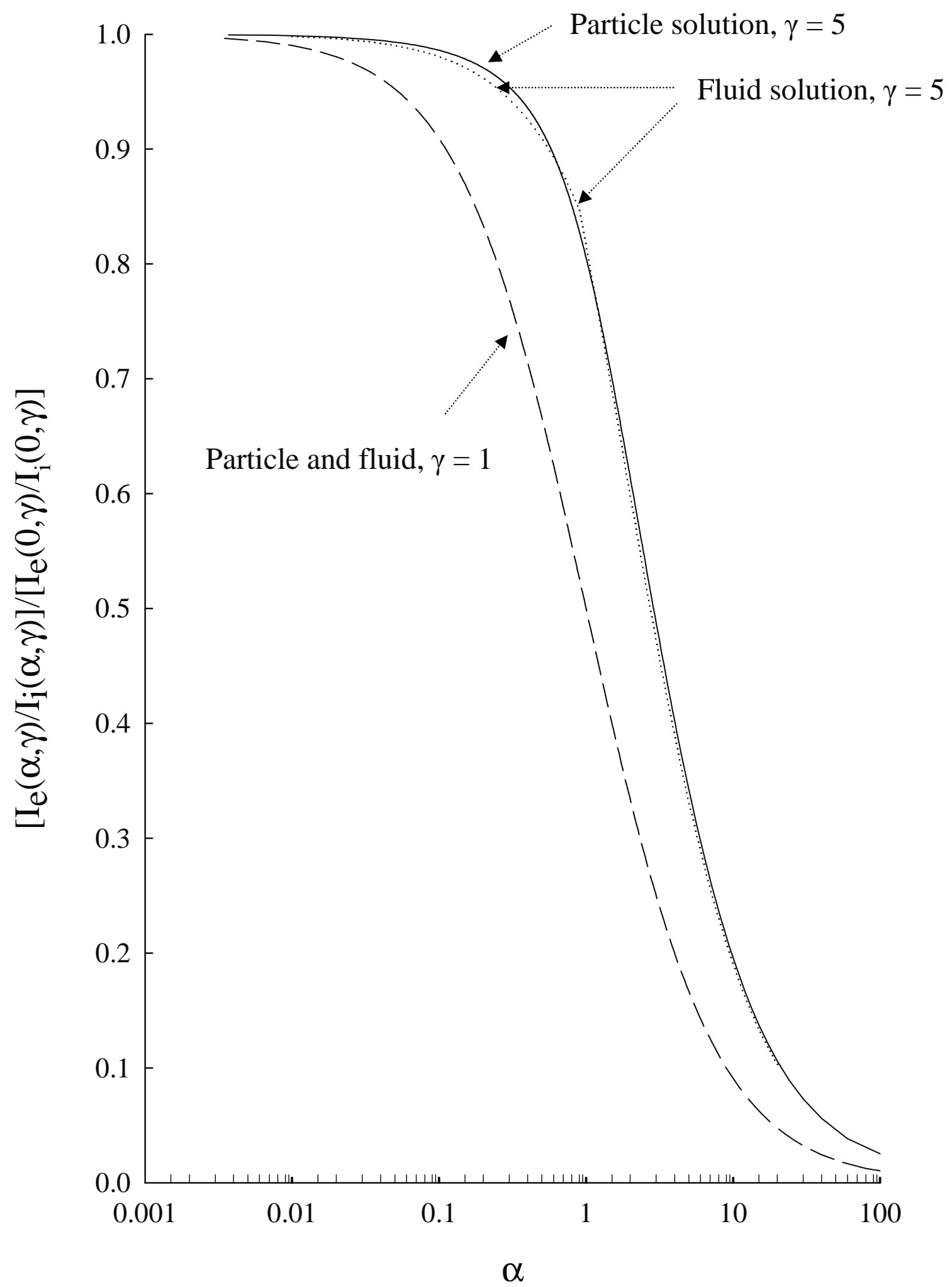

Figure 13 


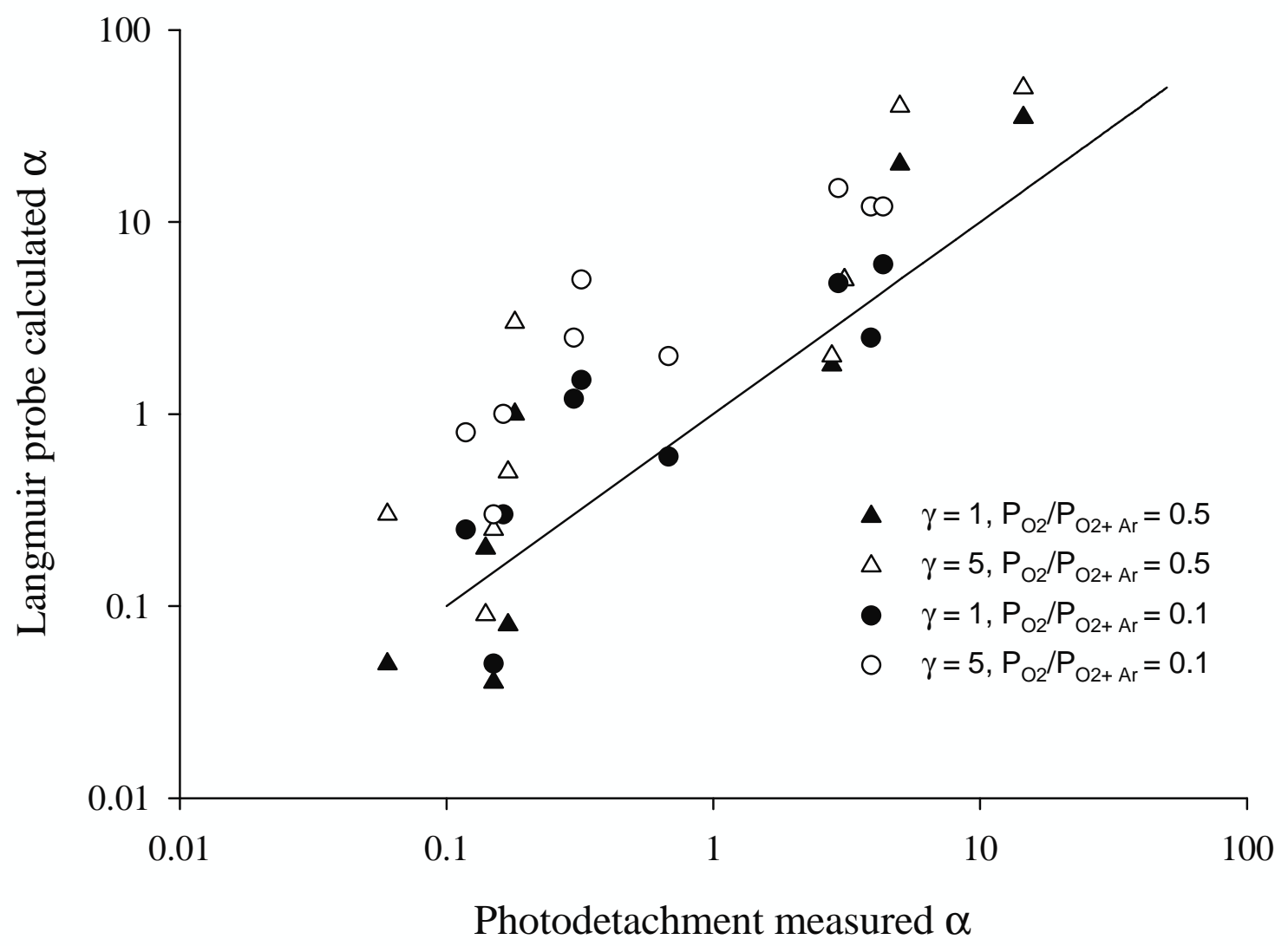

Figure 14 